\title{
Roles of land surface albedo and horizontal resolution on the Indian summer monsoon biases in a coupled ocean- atmosphere tropical-channel model
}

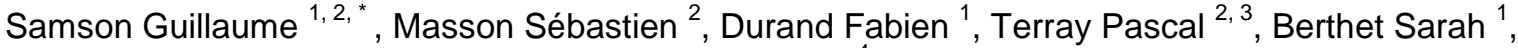 \\ Jullien Swen ${ }^{4}$
}

${ }^{1}$ LEGOS, UMR5566 CNRS-CNES-IRD-UPS, 14 Avenue Belin, 31400, Toulouse, France

${ }^{2}$ LOCEAN, Sorbonne Universités (UPMC, Univ Paris 06)-CNRS-IRD-MNHN, 4 place Jussieu, 75005, Paris, France

${ }^{3}$ Indo-French Cell for Water Sciences, IISc-NIO-IITM-IRD Joint International Laboratory, IITM, Pune, India

${ }^{4}$ LOPS, IFREMER, Univ. Brest, CNRS, IRD, IUEM, 29280, Brest, France

* Corresponding author : Guillaume Samson, email address : guillaume.samson.pro@gmail.com

\begin{abstract}
:
The Indian summer monsoon (ISM) simulated over the 1989-2009 period with a new $0.75^{\circ}$ oceanatmosphere coupled tropical-channel model extending from $45^{\circ} \mathrm{S}$ to $45^{\circ} \mathrm{N}$ is presented. The model biases are comparable to those commonly found in coupled global climate models (CGCMs): the Findlater jet is too weak, precipitations are underestimated over India while they are overestimated over the southwestern Indian Ocean, South-East Asia and the Maritime Continent. The ISM onset is delayed by several weeks, an error which is also very common in current CGCMs. We show that land surface temperature errors are a major source of the ISM low-level circulation and rainfall biases in our model: a cold bias over the Middle-East (ME) region weakens the Findlater jet while a warm bias over India strengthens the monsoon circulation over the southern Bay of Bengal. A surface radiative heat budget analysis reveals that the cold bias is due to an overestimated albedo in this desertic ME region. Two new simulations using a satellite-observed land albedo show a significant and robust improvement in terms of ISM circulation and precipitation. Furthermore, the ISM onset is shifted back by 1 month and becomes in phase with observations. Finally, a supplementary set of simulations at $0.25^{\circ}$-resolution confirms the robustness of our results and shows an additional reduction of the warm and dry bias over India. These findings highlight the strong sensitivity of the simulated ISM rainfall and its onset timing to the surface land heating pattern and amplitude, especially in the ME region. It also illustrates the keyrole of land surface processes and horizontal resolution for improving the ISM representation, and more generally the monsoons, in current CGCMs.
\end{abstract}

Keywords : Indian summer monsoon, Land surface albedo, Horizontal resolution, Precipitation biases, Monsoon onset, CGCM 
The Indian Summer Monsoon (ISM; see Table 1 for acronyms) brings substantial rainfall from June to September to some of the world most populated regions, whose economy relies mainly on agriculture and water resources. But despite recent progress in our understanding of mechanisms driving ISM precipitation, Coupled General Circulation Models (CGCMs) are still not able to correctly represent its main spatial and temporal characteristics (Sperber et al. 2013) and the skill of seasonal ISM predictions by dynamical or statistical models remains currently very low, contrary to what is observed in other tropical regions (Wang et al. 2015).

While some improvements have been achieved with the last generation of CGCMs, especially in terms of intraseasonal variability (Abhik et al. 2014, Sabeerali et al. 2013, Goswami et al. 2014), some basic features of the ISM, such as the onset or the rainfall spatial distribution, are still poorly captured with a persisting (wet) dry bias over (ocean) land (see Fig. 2 of Sperber et al. 2013).

The limited horizontal resolution of CGCMs is frequently listed as a major caveat because current coarse atmospheric models cannot properly resolve orography (Wu et al. 2002, Chakraborty et al. 2002, Cherchi and Navarra 2007, Boos and Hurley 2013), intraseasonal oscillations (Saha et al. 2013), tropical disturbances (Sabin et al. 2013) or convection (Pattnaik et al. 2013, Ganai et al. 2015), which all significantly contribute to the total ISM rainfall, especially in the monsoon trough region.

Regional Climate Models (RCMs) allow simulating the ISM at higher resolutions than global CGCMs, but with a strong control of the lateral boundaries imposed to the RCMs. This allows to distinguish the effects of local versus remote forcings on the ISM (Seo et al. 2009, Samala et al. 2013), to test the sensitivity of the simulated ISM to different physical parameterizations (Mukhopadhyay et al. 2010,

87 Srinivas et al. 2013, Samson et al. 2014) or to prescribe the orography in a more realistic way (Ma et al. 2014). But despite those specificities, significant biases still exist in terms of precipitation and surface temperature (Lucas-Picher et al. 2011),

90 which suggest that high resolution is not the unique missing ingredient in order to 91 improve ISM rainfall in current CGCMs and RCMs. 
Local and remote Sea Surface Temperature (SST) errors, amplified by oceanatmosphere coupling, can also adversely affect the coupled model performance in simulating the ISM rainfall or its onset timing, and has gained a lot of attention in recent years (Bollasina and Nigam 2009, Bollasina and Ming 2013, Levin and Turner 2012, Joseph et al. 2012, Prodhomme et al. 2014, 2015; among others). Common SST biases have been clearly identified in many CGCMs and their consequences on the ISM have been addressed in these studies. However, the specific origins of these SST errors are not well understood, they may vary from one CGCM to another and they cannot account alone for the ISM rainfall errors in current CGCMs (Prodhomme et al. 2014, 2015, Li et al. 2015).

Less attention has been paid to large-scale long-standing biases such as land temperature errors, which can also influence the ISM simulation (Christensen et al. 2007, Lucas-Picher et al. 2011, Boos and Hurley 2013). The ISM onset timing primarily depends on the meridional land-sea thermal contrast between the Indian subcontinent and the tropical Indian Ocean (IO) (Li and Yanai 1996, He et al. 2003, Xavier et al. 2007, Prodhomme et al. 2015). Consequently, models errors on Land

108 Surface Temperature (LST) can directly influence the ISM onset characteristics 109 (Prodhomme et al. 2015). Aside from the onset timing, the ISM structure and intensity 110 also depends on the meridional Tropospheric Temperature (TT) gradient, which relies 111 on both surface local and remote heat sources during boreal summer (Wu et al. 2009, 112 Bollasina and Nigam 2011, Dai et al. 2013). Hence, LST and TT biases can also 113 influence the ISM representation in the models. However, many studies suggest that 114 the orographic effects, mountains and TT errors are stronger than the direct impact of 115 the land surface heating on the ISM (He et al. 2003, Bollasina and Nigam 2011, 116 Molnar et al. 2010, Boos 2015). Especially, Boos and Kuang (2010, 2013) showed by 117 changing the Tibetan plateau albedo that this region is not a dominant heating source 118 for the atmosphere during the ISM, but rather a good insulator preventing mixing 119 between tropical warm and humid air with extra-tropical cold and dry air.

LST biases and their influence on the ISM have been relatively poorly studied compared to TT biases and errors due to orography (Kumar et al. 2014). The pioneering work of Charney et al. (1977) addressed the sensitivity of summer 123 monsoon regions to land surface heating by modifying the land albedo in their model. 124 They proposed a mechanism linking the land albedo with the monsoon strength. This 
mechanism was subsequently summarized by Meehl (1994): an increase in land albedo creates a decrease of the solar flux absorption leading to a colder land surface

127 and thus to a decreased land-sea thermal gradient. This decrease of the land-sea 128 contrast weakens the monsoon flow and the associated precipitation. This mechanism 129 has been further explored and confirmed by Meehl (1994) with various atmospheric 130 General Circulation Models (GCMs). Zhaohui and Qingcun (1997) showed some 131 improvements in the East Asian monsoon and associated rainfall in their GCM when using an observed climatological albedo. Using an idealized configuration, Chou 133 (2003) also showed that changing the land surface albedo can strengthen or weaken 134 the meridional TT gradient and, consequently, the ISM migration and intensity. 135 Furthermore, this method has been successfully used by Kelly and Mapes (2013) to 136 control the strength of the ISM in dedicated sensitivity experiments. Finally, Flaounas 137 et al. (2012) showed that lowering land albedo modifies the Inter-Tropical 138 Convergence Zone (ITCZ) position during the West African monsoon. In a nutshell, 139 the specific effect of land surface heating processes, versus orographic effects, on the monsoon is still an open problem (Kelly and Mapes 2010, Rajagopalan and Molnar 141 2013, Wu et al. 2012, Ma et al. 2014).

142 The present work aims at revisiting the relationship between land surface 143 albedo, surface heating and the ISM biases in a state-of-the-art Coupled Tropical 144 Channel Model (CTCM). Due to the significant ocean-atmosphere feedbacks involved 145 in ISM variability and seasonal cycle (Wang et al. 2005), our work is based on a 146 coupled model, rather than a forced atmospheric model as done in many previous studies. We demonstrate that constraining land surface heating by using an observed 148 albedo climatology leads to significant improvements in ISM simulation in our 149 CTCM, especially in terms of the ISM rainfall onset and climatology. Moreover, we 150 illustrate that our results are valid in both coupled and forced frameworks with several 151 dedicated experiments, highlighting the robustness of our findings. The paper is 152 organized as follows. Section 2 provides a detailed description of the CTCM, the 153 experimental setup and observed datasets used in our analysis. Section 3 describes the 154 ISM mean characteristics and biases simulated with the CTCM. The sensitivity of the 155 ISM to the land surface albedo and horizontal resolution is further analyzed in Section 1564 with the help of sensitivity experiments. Finally, Section 5 provides a summary of 157 our findings. 


\section{Model description and experimental setup}

The CTCM is composed of the WRF-ARW v3.3.1 atmospheric model

163 (Skamarock and Klemp 2008) and the NEMO v3.4 ocean model (Madec 2008)

164 coupled through the OASISv3-MCT coupler (Valcke et al. 2013).

165 The oceanic and atmospheric components share an identical horizontal grid 166 discretization (Arakawa-C grid), projection (Mercator) and resolution $\left(0.75\right.$ or $0.25^{\circ}$ ).

167 The standard horizontal resolution used here is $0.75^{\circ}$, but some of our sensitivity 168 experiments (described later in Section 2.b) use a $0.25^{\circ}$ horizontal resolution in order 169 to asses the robustness of our results with respect to the model resolution. The CTCM 170 domain extends from $45^{\circ} \mathrm{S}$ to $45^{\circ} \mathrm{N}$, covering about $70 \%$ of the earth surface. 171 Consequently, the extratropics (poleward of $45^{\circ}$ of latitude) can exert an influence on 172 the CTCM through the lateral atmospheric and oceanic forcings, but the model is also 173 able to generate its own tropical internal variability at all the timescales, as seen from 174 the simulated El Niño events, which timing does not match the observed El Niño 175 events during the 1989-2009 period (not shown). This original model configuration 176 presents several advantages compared to the classical GCMs and RCMs approaches. 177 Compared to RCMs, the tropical-channel configuration is not subject to issues related 178 to domain size, which can influence the realism of the model solution (Leduc and 179 Laprise 2009, Dash et al. 2015). Because of the absence of meridional boundaries, the 180 model is also able to simulate zonally-propagating atmospheric and oceanic waves in 181 a coherent way, as well as zonal teleconnections and remote tropical forcings. 182 Consequently, this model avoids an important caveat observed with RCMs, which can 183 generate spurious circulations and precipitations along their meridional boundaries in 184 zonal flows (Hagos et al. 2013). Such tropical-channel configuration has 185 demonstrated its usefulness to study tropical waves activity, such as the Madden186 Julian Oscillation (Ray et al. 2011, Ulate et al. 2015) and inertia-gravity waves (Evan 187 et al. 2012). Compared to GCMs, the model does not include the extratropics, which 188 limits the inclusion of additional errors and reduces the simulation computational cost. 
The ocean vertical grid has 75 z-levels, with 25 levels above $100 \mathrm{~m}$ and a resolution ranging from $1 \mathrm{~m}$ at the surface to $200 \mathrm{~m}$ at the bottom. Partial filling of the 191 deepest cells is allowed. The atmospheric grid has 60 eta-levels with a top of the 192 atmosphere located at $50 \mathrm{hPa}$. The WRF default vertical resolution has been 193 multiplied by three below $800 \mathrm{hPa}$. Thus, the first 33 levels are located below $500 \mathrm{hPa}$ 194 with a vertical resolution of $2 \mathrm{hPa}$ near the surface. The vertical resolution then 195 decreases to $\sim 50 \mathrm{hPa}$ around $800 \mathrm{hPa}$ and increases again when approaching the top 196 of the model with $\sim 6 \mathrm{hPa}$ for the top level.

The WRF model can be configured with an important choice of physical schemes. In this study, the model physical setup is the same as in Samson et al. (2014), who showed that a NEMO-OASIS-WRF (NOW) regional coupled model is 200 able to realistically simulate the tropical IO climate, including the ISM main 201 characteristics. This physical package is listed here: the longwave Rapid Radiative 202 Transfer Model (RRTM; Mlawer et al. 1997), the "Goddard" Short Wave (SW) 203 radiation scheme (Chou and Suarez 1999), the "WSM6" microphysics scheme (Hong 204 and Lim 2006), the Betts-Miller-Janjic (BMJ) convection scheme (Betts and Miller 205 1986; Janjic 1994), Yonsei University (YSU) planetary boundary layer scheme (Hong 206 et al. 2006), the unified NOAH Land Surface Model (LSM) with the surface layer 207 scheme from MM5 (Chen and Dudhia 2001). Mukhopadhyay et al. (2010) and 208 Samson et al. (2014) shown that the BMJ convection scheme produces a reasonable 209 ISM climatology in both forced and coupled WRF configurations, respectively. 210 Supplementary sensitivity tests have been performed with different sets of physical 211 parameterizations, but with no clear improvement when compared to the selected set. 212 A brief description of these sensitivity tests is given below and a more complete 213 analysis of the sensitivity of the simulated tropical mean state to various model 214 parameters can be found in Crétat et al. (2016). Thus, this study uses a well-tested 215 suite of parameterization schemes for the WRF model.

216 The oceanic component is based on NEMO (Nucleus for European Modeling 217 of the Ocean numerical framework) version 3.4 (Madec 2008). The set of physical 218 parameters employed here is similar to the set used for the default global 219 configuration at $1^{\circ}$-resolution (Voldoire et al. 2013). The lateral diffusion scheme for 220 tracers is an iso-neutral Laplacian with a constant coefficient of $1000 \mathrm{~m}^{2} / \mathrm{s}$. Tracer 221 advection is treated with a total variance dissipation scheme (Lévy et al. 2001) with 
an additional term coming from the eddy-induced velocity parameterization (Gent and

223 Mcwilliams 1990) with a space and time variable coefficient (Tréguier et al. 1997).

224 The lateral diffusion of momentum is a horizontal Laplacian with an eddy viscosity of

$22510000 \mathrm{~m}^{2} / \mathrm{s}$, which is reduced to $1000 \mathrm{~m}^{2} / \mathrm{s}$ in the $2.5^{\circ} \mathrm{S}-2.5^{\circ} \mathrm{N}$ equatorial band, out of

226 the western boundaries regions. The vertical mixing is parameterized using an

227 improved version of turbulent kinetic energy closure scheme (Blanke and Delecluse

228 1993) with a Langmuir cell (Axell 2002) and a surface wave breaking

229 parameterization (Mellor and Blumberg 2004).

230 The OASIS coupler exchanges the surface fields between the models every 2

231 hours without any spatial interpolation as the models are using the same horizontal

232 grid (see Samson et al. 2014 for details). Such a high coupling frequency is crucial in

233 the tropics to correctly represent the solar diurnal cycle effect on the ocean. It has

234 been shown that high-frequency coupling is instrumental in representing

235 realistically the monsoon dynamics (Terray et al. 2012) as well as air-sea scale

236 interactions from small scales to large scales and up to ENSO variability (Masson

237 et al. 2012). There is no restoring of any kind in atmosphere and ocean. Initial state

238 and boundary conditions come from the ERA-Interim reanalysis (Dee et al. 2011) for

239 the atmospheric component and from the Drakkar $0.25^{\circ}$-resolution global ocean

240 model (Barnier et al. 2007) for the oceanic component over the 1989-2009 period.

2.2. Experimental Setup

243 The reference simulation (ALB1 hereafter) described in the previous 244 paragraph is compared with three different sets of simulations. Table 2 summarizes all 245 the model simulations used in this study.

246 A first set of four 10-years atmospheric simulations forced with observed SST 247 (sensitivity set hereafter) is used to assess the sensitivity of the simulated ISM biases 248 to the SST errors (due to the coupling with the ocean model), to the model resolution 249 and to the atmospheric SW and convective schemes. In this sensitivity set of forced 250 simulations, the FORC simulation is similar to the ALB1 simulation, except that the 251 atmospheric model is forced with observed SSTs from version 2 of the $0.25^{\circ}$ daily 252 optimum interpolation SST analysis from the NOAA (Reynolds et al. 2007). The 253 HIRES simulation differs from FORC by its horizontal resolution of $0.25^{\circ}$ instead of 
$0.75^{\circ}$. The CONV simulation is the same as FORC, but with a different convection scheme (Kain-Fritsch instead of the BMJ scheme; Kain 2004). Finally, the RAD simulation is similar to FORC, but with a different short-wave radiation scheme

257 (Dudhia scheme instead of the Goddard scheme; Dudhia 1989). These forced 258 atmospheric simulations will be analyzed in Section 3.

The second set of simulations (albedo set hereafter) is composed of two additional 20-years fully coupled CTCM simulations identical to the ALB1 simulation, except for the land surface albedo used in the CTCM. In this second set of coupled simulations, two different background land surface albedo fields are employed as explained below. These simulations will be analyzed in Section 4.

The NOAH LSM version available with WRF uses a simplified and direct method to compute the SW fluxes at the surface. This LSM only considers the broadband SW wavelength, which means that no distinction is made between visible and infrared wavelength albedos. The albedo dependence to the solar zenith angle is also neglected. Moreover, no distinction can be made between the diffuse and the direct components of solar radiation, as they are not available in the WRF version used in this study. In this simplified context, albedo associated with the diffuse SW component (i.e. white-sky) is neglected and the total incoming solar flux is considered as purely direct. Consequently, the NOAH LSM uses a snow-free direct (e.g. blacksky at local noon) background SW broadband albedo climatology to compute the SW

274 fluxes at the surface during the simulation. Two methods are available in WRF to 275 prescribe this land surface albedo monthly climatology.

In the CTCM reference simulation (ALB1), albedo extreme values (annual minimum and maximum) are associated with a dominant land-use category. A weighted average is then computed between the two albedo extreme values depending on the corresponding climatological monthly green fraction. Consequently, the albedo

280 is equal to its minimum (maximum) annual value when the green fraction is 281 maximum (minimum). The land-use dataset used by the NOAH LSM is the 282 MODerate resolution Imaging Spectroradiometer (MODIS) land-cover classification 283 of the International Geosphere-Biosphere Program (IGBP; Friedl et al. 2002) and 284 modified for the NOAH LSM (lakes detection and 3 new categories (18-19-20) have been added). The dataset has been updated with MODIS data up to March 2011 (see WRF FAQ link) and the annual climatology of this dataset is displayed in Fig. 1a. The 
vegetation fraction used by the NOAH LSM is the NESDIS/NOAA $0.144^{\circ}$ monthly annual cycle of the vegetation greenness fraction dataset (Gutman and Ignatov 1998). This dataset is a 5-year (1985-1990) climatology of the Advanced Very HighResolution Radiometer (AVHRR) vegetation index.

The second method available with WRF consists of directly prescribing a snow-free black-sky SW broadband albedo climatology. The albedo dataset provided with WRF for the NOAH LSM is the NESDIS/NOAA $0.144^{\circ}$ monthly 5-year climatology surface albedo derived from the AVHRR satellite (henceforth AVHRR product; Csiszar and Gutman 1999). The error analysis performed in Csiszar and Gutman (1999) suggests that the AVHRR surface albedo is retrieved with 10 to $15 \%$ relative accuracy. The simulation using this prescribed albedo is referred as ALB2 hereafter.

In order to test the robustness of our results, a third CTCM simulation using an up-to-date snow-free black-sky SW broadband albedo climatology estimated from MODIS data (henceforth MODIS product; Schaaf et al. 2011) has also been performed (ALB3 in Table 2). This MODIS albedo dataset is described in the next paragraph and its annual climatology is presented in Fig. 1b. This simulation gave results very similar to ALB2 despite the fact that the MODIS albedo is slightly higher than the NESDIS/NOAA albedo used in ALB2 (Fig. 1d). This confirms the robustness of the results obtained with ALB2. Results from ALB3 are consequently not shown in this study for conciseness, but demonstrate that our results are independent of the observed albedo product used in the simulations.

Finally, two more coupled simulations similar to ALB1 and ALB2

310 respectively have been performed but with a horizontal resolution of $0.25^{\circ}$ instead of

$3110.75^{\circ}$ in order to demonstrate the robustness of our results with respect to the 312 resolution used in the CTCM ("High-Resolution Set" in Table 2). These two high313 resolution coupled simulations (ALB1HR and ALB2HR, respectively) are also 314 analyzed in order to determine the cumulative (positive) effects of both an increased 315 spatial resolution and a change of the albedo on the simulated ISM characteristics by 316 the CTCM. The results from ALB1HR and ALB2HR are discussed in Section 4. 
Several datasets are used in this study. First, the two NOAH snow-free albedo fields (ALB1 and ALB2) are compared with the MODIS snow-free gap-filled blacksky SW broadband albedo product MCD43GF-v5 (Schaaf et al. 2011). This product is generated by merging data from the Terra and Aqua platforms produced every 8 days, with 16-days acquisition and available on a $0.05^{\circ}$ global grid. It is important to note that some regions are systematically masked by clouds during monsoon months, which makes direct albedo measurements difficult, or even impossible (Rechid et al. 2009). A temporal interpolation is applied to fill these missing values. The MODIS snow-free climatology is computed over the 2003-2013 period and is presented in Fig. 1b. The accuracy of this product is about $2 \%$ when compared to ground observations (Jin et al. 2003, Wang et al. 2004). The differences between NOAH LSM and MODIS snow-free albedo annual climatologies, as well as between the AVHRR and MODIS, are presented in Figs. 1c-d, respectively. We also use the MODIS MCD43C3-v5 product to validate output model surface albedo, which also includes the snow cover effect. This dataset is identical to the MCD43GF-v5 product, but surface data including snow covered areas are included in the processing.

Model precipitation is compared with the monthly $0.25^{\circ}$ Tropical Rainfall Measuring Mission (TRMM) 3B43-v7 rainfall product (Huffman et al. 2010) averaged over the 1998-2014 period. This dataset combines the 3-hourly merged high-quality/infrared estimates with the monthly-accumulated Global Precipitation Climatology Centre (GPCC) rain gauge analysis. Monthly climatological fields such as surface temperature, wind and Sea-Level Pressure (SLP) are derived from the $0.75^{\circ}$

341 ERA-Interim reanalysis (Dee et al. 2001) averaged over the 1989-2009 period. 342 Finally, surface radiative heat budget is computed from the monthly $1^{\circ}$ CERESEBAF v2.8 product (Kato et al. 2013) over the 2001-2012 period.

\section{ISM biases in ALB1 simulation and the sensitivity set} their capability to correctly reproduce the main features of the climate system. More specifically, the simulation of a realistic boreal summer precipitation climatology is a primary requirement that a model should possess for monsoon studies, but it remains 
351 a difficult task for current state of the art CGCMs (Sperber et al. 2013, Prodhomme et 352 al. 2014, Annamalai et al. 2015). As a first step, we thus examine in this section the 353 systematic errors that characterize the climatologies of rainfall, low-level winds, 354 surface temperature and SLP simulated in the reference run (ALB1) of the CTCM 355 during boreal summer (JJAS). The possible origins of these systematic errors are then 356 investigated with the help of several dedicated experiments performed with the forced 357 atmospheric component of the CTCM (see Section 2.b for details about these experiments). Annual cycles of simulated ISM rainfall indices are also discussed.

\subsection{ISM description in observations and ALB1 control simulation}

The climate of South Asia is dominated by the monsoon. During boreal summer, a strong inter-hemispheric SLP gradient is observed over the Indian Ocean area, with a deep low centered over Pakistan and northwestern India (Fig. 2a). The close correspondence between SLP and surface temperature over northwest India suggests that the intense solar heating over the northern hemisphere during spring and summer favors the development of this low. This explains why this deep low is often referred as a "heat" low in the literature (Flohn 1968). However, orography and diabatic heating over the Bay of Bengal $(\mathrm{BoB})$ also exert a dominant control on the deepening of this low during the rainy season through remotely forced subsidence over Iran-Turkmenistan-Afghanistan and the Rodwell-Hoskins'monsoon-desert mechanism (Yanai et al. 1992, Rodwell and Hoskins 1996, Bollasina and Nigam 2011). This "heat" low is connected to a tilted band of low SLP extending from the northern $\mathrm{BoB}$ to northwest India over the Indo-Gangetic plain, which is usually referred to as the monsoon trough. The monsoon trough is the signature of transient Low-Pressure Systems (LPSs) propagating inland from the BoB during the summer monsoon (Krishnamurthy and Ajayamohan 2011).

As expected, the large inter-hemispheric SLP gradient over the Indian domain generates vigorous cross-equatorial southerly monsoonal winds over the western 379 IO/east African highlands (Fig. 2d). Due to the Coriolis effect, this monsoon low380 level flow gradually becomes westerly over the Arabian Sea (AS), resulting in a 381 strong moisture flux toward the Asian landmass and bringing abundant rainfall over South Asia during boreal summer. 
Precipitation increases sharply from April to June, which corresponds to the monsoon onset and the sudden "jump" of the ITCZ from its oceanic to continental position during boreal summer (Fig. 3; see Wang 2006). The orography provides anchor points where monsoon rainfall maxima are located, especially along the Western Ghats, the Burmese coast and the Philippines (Fig. 2d). Abundant rainfall is also observed over the Gangetic plain and the foothills of Himalaya associated with the LPSs propagating from the $\mathrm{BoB}$ into northwest India during the summer monsoon (Krishnamurthy and Ajayamohan 2011). During this season, SST maximum is observed in the eastern equatorial IO, while the western AS is characterized by colder SSTs as a result of coastal upwelling and strong evaporation in response to the strong southwesterly alongshore winds (Figs. 2a and d) (de Boyer Montégut et al. 2007). This low-level jet (the so-called Findlater jet) and the associated cold SSTs prevent atmospheric deep convection to occur in the western part of the basin (Gadgil et al. 1984).

The spatial pattern of the JJAS precipitation bias in ALB1 (Fig. 2f) exhibits many similarities with the systematic errors commonly observed in CMIP5 models (see Sperber et al. 2013; Sooraj et al. 2015). In particular, a dry bias is present over the Indian subcontinent with two maxima along the Ghats and over the foothills of the Himalaya. A relationship exists between precipitation biases and $850 \mathrm{hPa}$ wind biases in regions where orographic forcing is important. A rainfall dry (wet) bias is usually associated with an underestimation (overestimation) of the low-level wind in these regions. Deficient rainfall is also simulated over the monsoon core region $\left(65^{\circ}-100^{\circ} \mathrm{E}\right.$ $/ 5^{\circ}-30^{\circ} \mathrm{N}$ ) suggesting that the whole ISM is too weak in ALB1. The simulated ISM rainfall annual cycle over the continent is very poor, to say the best, with a monthly maximum hardly reaching $6 \mathrm{~mm}$ /day in August (Fig. 3a). Moreover, ISM onset is delayed by almost 2 months in ALB1 (Figs. 3a-b). Consequently, the dry bias observed over India during boreal summer (Figs. 2e-f) is due to underestimated precipitation intensity, but also to a significant underestimation of the duration of the rainy season. Consistently, the Findlater jet is significantly underestimated, too much zonal, and its northward extension is limited to $15^{\circ} \mathrm{N}$ in the CTCM instead of $20-25^{\circ} \mathrm{N}$ in ERA-Interim (Figs. 2d-f).

Excessive rainfall is present over the south-eastern AS, reflecting again this limited northward propagation of the ITCZ during boreal summer in ALB1 (Fig. 2f). 
This wet bias is usually associated with warmer-than-observed local SST as a

417 consequence of a too weak monsoon flow, reduced latent heat loss and under418 representation of the upwelling along the Somali and Omani coasts in our CTCM and 419 in CMIP5 models (Fig. 2c; Prodhomme et al. 2014, Li et al. 2015). East Asia and 420 South China Sea also exhibit excessive rainfall associated with overestimated 421 westerly low-level winds over eastern equatorial IO and South China Sea in the 422 CTCM (Fig. 2f).

SST biases are moderate with a warm bias slightly exceeding $2{ }^{\circ} \mathrm{C}$ in the western tropical IO (Fig. 2c), as discussed above. The largest surface temperature biases are found over land with a maximum warm bias slightly exceeding $10^{\circ} \mathrm{C}$ over most of central and northern India. A warm bias of $\sim 3^{\circ} \mathrm{C}$ is also observed over South-

427 East Asia and over the Maritime Continent despite the excessive rainfall simulated in 428 these regions. On the contrary, cold surface temperature biases are found (i) over the 429 western part of the Tibetan plateau, suggesting an indirect effect of overestimated 430 snow and precipitation over this elevated area during boreal winter (not shown) and 431 (ii) in the desertic region extending from Pakistan to Afghanistan, Iran and over the 432 Arabic Peninsula. This region will be referred as the "Middle-East" (ME) region 433 hereafter for simplicity.

Simulated SLP also exhibits significant biases with lower-than-observed SLP over most of the domain, except in the ME region where a positive SLP bias of several $\mathrm{hPa}$ is found. The low-pressure bias is maximum over the core monsoon region and along the Himalayan foothills. This SLP bias is also commonly observed in CMIP5 models as shown by Sooraj et al. (2015; see their Fig. 3d). As a consequence, the SLP minimum located over the ME region in ERA-Interim is shifted eastward over the monsoon trough region in ALB1 (Figs. 2a-b). The large dry bias

441 over the monsoon trough region in ALB1 suggests that LPSs and clouds are less than 442 observed or even absent in this region during boreal summer and, hence, that the low443 pressure bias is not related to excessive LPSs, but rather to the strong warm surface 444 temperature bias. In turn, this excessive land-surface heating may result from reduced 445 rainfall and clouds associated with the absence of these LPSs over this region. Indeed, 446 the ITCZ is locked over the ocean in ALB1, southward of its observed position (Figs. 447 2e-f). Alternatively, the warm bias may also be related to deficient land processes in 448 the CTCM, as we will see in the next section. 
3.2. ISM biases in sensitivity experiments

Various mechanisms have been proposed to explain the dry bias and the delayed monsoon onset over the Indian landmass simulated by current CGCMs (see Introduction). To explore these various potential sources of errors in our modeling framework, the "sensitivity" set of simulations is analyzed in this section (see Section 2 and Table 2 for further details). All configurations, excepted FORC and HIRES, underestimate the total amount of rainfall during the monsoon season. In most cases, this is related to dry conditions over land (Fig. 3a), but also to an ISM onset delayed by almost 2 months over land (except HIRES) as in ALB1. Figure 4 further illustrates model sensitivity to changes in the ocean-atmosphere coupling, the physics and the resolution used:

A first source of model errors is the coupling with an ocean model and the resulting SST errors. Compared to ALB1, the onset delay is attenuated and the total precipitation is increased in FORC (Figs. 3 and 4a, first line). Nonetheless, the monsoon peak time and withdrawal time remain delayed, especially when considering land areas (Fig. 3b). There is also a strong spatial compensation of rainfall error patterns between north India and the BoB in FORC, as in ALB1, and the warm (cold) bias is still present in northern and east India (Pakistan), but is attenuated over southern India (Fig. 4a).

\section{- Resolution (HIRES)}

Higher horizontal resolution induces a better simulation of orographic precipitation. The improved Himalayan orography also prevents mixing between cold and dry air from mid-latitudes with warm and moist air from the tropics, allowing a stronger TT gradient and hence a more intense and realistic ISM (Boos et al. 2010; 2013). HIRES significantly improves the precipitation seasonal cycle with a maximum reached in July as in observations (Fig. 3). However, the dry bias persists over India, especially along the Western Ghats and in the northern and eastern BoB, although it is well attenuated compared to FORC (Fig. 4b). The same holds for the warm temperature bias, which is still present, but attenuated over northern India in HIRES. Nevertheless, it is noteworthy that the spatial patterns of rainfall, low-level 
481

482

483

484

485

486

487

488

489

490

491

492

493

494

495

496

497

wind and temperature errors remain basically the same as in the FORC experiment (Figs. 4a-b).

- Physics (RAD and CONV)

CONV and RAD experiments suffer from the same deficiencies, with a dry bias - even more pronounced - over India and a more southward and oceanic position of the ITCZ (Figs. 4c and d). Pronounced wet biases are also found over the Maritime Continent, the eastern equatorial IO and China in CONV, and along a line extending from the equatorial IO to the South China Sea in RAD. The warm bias over India is also present in these two simulations, even if it is well attenuated in RAD. On the other hand, the use of the Dudhia (1989) radiation scheme leads to an enhancement of the ME cold bias and to an erroneous zonal surface temperature gradient between this region and South Asia, suggesting that these surface temperature variations do affect the latitudinal position of the ITCZ during boreal summer (Fig. 4d).

In a nutshell, the ISM and associated precipitation patterns are very sensitive to the model configuration settings. Our SST-forced and high-resolution simulations show significant improvements in terms of precipitation amount and seasonal cycle, even if dry and warm biases persist over North India. On the contrary, our convective and radiative sensitivity tests show a clear deterioration of the simulated ISM with a further increased dry bias over India and an even more southward and oceanic position of the ITCZ compared to the other simulations (e.g. ALB1, FORC and HIRES). Finally, the improvements or degradations in the simulated rainfall concern mainly the amplitude of the rainfall biases over land and ocean, not the spatial pattern of these systematic errors: in all these sensitivity experiments, as in ALB1, we observe excess rain over the ocean compared to observations, especially in the southern part of the BoB (FORC, HIRES and RAD) and the southeastern AS (FORC and RAD), and dry conditions over the land, especially along the Western Ghats and over the monsoon core region.

\subsection{Surface temperature and SLP biases origins}

All sensitivity simulations systematically present a high-pressure bias over the ME region and a low-pressure bias over India and southeast Asia (Fig. 4, right column). More intriguingly, all the configurations, including HIRES, exhibit similar 
513 spatial pattern of skin temperature errors during the monsoon season with warmer-

514 than-observed surface temperature over the core monsoon region and the foothills of

515 the Himalaya, and cooler-than-observed surface temperature over the ME region. This

516 seems to induce significant errors in the SLP field due to erroneous surface heating

517 forcing over the land. It is noteworthy, that these surface temperature errors are also

518 present in HIRES, despite reduction of the rainfall dry bias over the monsoon trough

519 region in this simulation. This suggests that at least part of these temperature errors

520 are not due to reduced cloudiness and evaporation over the Indo-Gangetic plain, but to

521 other reasons related to land processes.

522 Figure 5 shows the observed surface temperature and SLP climatologies 523 during the spring season (March-April-May) preceding the ISM onset and the 524 corresponding ALB1 biases. In observations (Fig. 5a), the surface temperature and 525 SLP patterns are strikingly different from the JJAS period, especially in the ME 526 region where the surface heating remains small compared to what is observed during 527 the monsoon season. On the contrary, India and South Asia are much warmer during 528 spring than during JJAS since the incident solar radiation is not balanced by clouds 529 and precipitation cooling as during the monsoon. Consequently, the land temperature 530 warming is very homogenous during spring. This is also true for the tropical IO, as no 531 significant SST gradient is present during this season. The model captures quite well 532 this homogenous spatial pattern in terms of surface temperature (pattern correlation = 533 0.95) and SLP (Fig. 5b). But surface temperature biases, previously described during 534 JJAS, are already present during the pre-monsoon hot and dry season with a strong 535 warm (cold) bias over India and South-East Asia (Tibetan plateau) and a relatively 536 smaller cold bias in the ME. This suggests that surface temperature biases observed 537 during the monsoon already exist before the monsoon onset and are thus not solely 538 related to the dry bias and improper ITCZ position simulated during JJAS in ALB1. 539 This is further explored in the next sections with more detailed diagnostics and the 540 "albedo" set of coupled experiments.

542 4. Effect of changing the land surface albedo on the ISM biases 
As discussed in the previous section, the warm bias over India cannot be entirely related to the dry bias during ISM and this dry bias is not due to SST errors since it persists in the forced-atmospheric experiments. The same stands for the cold

547 bias over the ME region, which already exists before the monsoon season (Fig. 5c).

548 Consequently, it appears that the model biases are at least partly related to the land

549 surface properties. In this section, we focus on the effect of changing the land surface 550 albedo on the ISM biases by comparing ALB1 and ALB2 coupled simulations.

\section{1}

\subsection{ALB1-ALB2 albedo comparison}

As seen in Figure 1c, ALB1 snow-free albedo annual climatology is affected by significant biases when compared to MODIS. ALB1 albedo is globally higher than MODIS, even if some significant underestimations are seen in the North African desert and some other local areas. The positive errors can reach $\sim 20 \%$ in some regions such as the Andes mountains, the Tibetan plateau and the Iran-TurkmenistanAfghanistan region. These errors are mainly due to the fact that the number of landuse categories is too limited to correctly represent the diversity of land surfaces at a regional scale. For example, the same albedo value $(0.38)$ is used in all the desertic regions, while their albedo can vary significantly according to their surface composition (e.g. black rocks vs white sand). Consequently, this simplified approach can lead to important differences when compared to in situ or satellite-based observed 564 albedo, especially in arid regions (Fig. 1c). On the contrary, ALB2 snow-free albedo 565 climatology, derived from AVHRR albedo product, is relatively close to the MODIS 566 snow-free product with an overall underestimation of about $5 \%$, except in some 567 regions such as India and South-East Asia where the albedo is slightly overestimated 568 (Fig. 1d).

Figures 6a-b show the JJAS total albedo (e.g. including snow effect) 570 differences between ALB2 and ALB1 simulations and ALB2 biases compared to the 571 corresponding MODIS product (also including snow effects). ALB2 albedo is almost 572 everywhere lower than ALB1 with maximum differences located in the ME region, 573 on the western Tibetan plateau and along the Himalaya mountains. The differences in 574 high-elevated areas are mainly due to differences in the snow cover, with less snow in 575 ALB2 compared to ALB1 (not shown). But despite a smaller snow cover, ALB2 
albedo is still overestimated in these mountainous regions when compared to MODIS because snow albedo is much higher than bare soil albedo (Fig. 6b). Various reasons can explain this bias: too much snow during boreal winter, unrealistic snow melting (e.g. too slow) due to improper LSM physics or snow albedo parameterization, which prevent the spring snow melt. Except in these snowy and elevated regions, ALB2 biases do not exceed 5\% in the considered domain. Maximum albedo differences reaching locally $\sim 30 \%$ between ALB1 and ALB2 are located in the ME region (Fig. 6a). This area is also affected by a cold bias in the various forced simulations analyzed in Section 3. To investigate the relationship between this cold bias and the land surface albedo and to quantify the sensitivity of the LST to albedo, a surface radiation budget analysis is performed over a box covering the $\mathrm{ME}$ region $\left(40^{\circ}-70^{\circ} \mathrm{E} /\right.$ $\left.15^{\circ}-37^{\circ} \mathrm{N}\right)$.

\subsection{Albedo radiative effect over the Middle-East region}

The various terms of the land surface radiative heat budget in the simulations are compared and validated against the CERES-EBAF dataset in Figure 7. In both simulations, the land surface receives too much downward SW flux ( 40 W.m $\left.{ }^{-2}\right)$ when compared to CERES-EBAF observations (Fig. 7a). This bias is related to the "Goddard" SW scheme, which tends to overestimate the SW downward flux at the surface (Crétat et al. 2016). However, the fraction of SW downward flux reflected by the surface varies according to the background albedo used in the simulations (Fig. 7b). Consequently, the lower albedo in ALB2 simulation efficiently decreases the upward SW flux (by about $40 \mathrm{~W} . \mathrm{m}^{-2}$ ) and the land surface receives a higher net SW flux (30 to $35 \mathrm{~W} . \mathrm{m}^{-2}$ ) compared to ALB1 and CERES-EBAF. This additional SW flux induces a higher LST in ALB2 (Fig. 6c). In turn, this higher LST induces an increased upward longwave (LW) flux emitted by the surface $\left(\sim 20 \mathrm{~W} \cdot \mathrm{m}^{-2}\right)$, which results in a higher net $\mathrm{LW}$ heat loss $\left(\sim 10 \mathrm{~W} \cdot \mathrm{m}^{-2}\right)$ in ALB2 than in ALB1 (Fig. 7b). Finally, the net radiative flux is underestimated in ALB1 by $\sim 10 \mathrm{~W} \cdot \mathrm{m}^{-2}$ while it is overestimated by $\sim 15 \mathrm{~W} \cdot \mathrm{m}^{-2}$ in ALB2 compared to CERES-EBAF. It corresponds to a difference between ALB1 and ALB2 of $\sim 25$ W.m ${ }^{-2}$. These differences are significantly greater than the CERES land surface LW and SW root-mean-square errors given by Kato et al. (2013), which both amount to about $8 \mathrm{~W} \cdot \mathrm{m}^{-2}$, respectively. 
As we said, this modification of the surface radiative budget in ALB2

611 compared to ALB1 induces a strong warming over the ME region ranging from 2 to

$6125^{\circ} \mathrm{C}$ (Fig. $6 \mathrm{c}$ ). A robust $\left(\mathrm{r}^{2}=0.6\right)$ and negative $\left(-0.2^{\circ} \mathrm{C}\right.$ when albedo increases by $\left.1 \%\right)$

613 relation is found when we compare the Middle-East JJAS mean climatological surface

614 temperature difference between ALB2 and ALB1 with the albedo difference between

615 ALB2 and ALB1. As a consequence, the cold bias observed in ALB1 turns into a 616 warm bias in ALB2 (Fig. 6d). A warming of the Tibetan plateau locally reaching $61710^{\circ} \mathrm{C}$ is also simulated in ALB2 compared to ALB1 (Fig. 6c). It can be explained by 618 the lower snow-free albedo in ALB2 compared to ALB1, as for the ME region. 619 Consequently, the cold bias is also reduced in this area (compare Figs. 2c and 6d).

620 On the contrary, a surface cooling is observed in ALB2 over the eastern part 621 of the domain (Fig. 6c). The colder area extends from southern India through northern 622 China. Consequently, the significant warm bias present over southern India and 623 South-East Asia in ALB1 is slightly reduced when compared to the ERA-Interim LST 624 (Fig. 6d). However, this surface cooling is not directly related to the local albedo because it is slightly lower in ALB2 than in ALB1, which would contribute to warm 626 the surface in these regions. On the other hand, no significant LST change is observed 627 over the foothills of Himalaya. Finally, the SST is not significantly affected by the 628 albedo change, except in the upwelling region along the Omani coast, which is about $629 \sim 1.5^{\circ} \mathrm{C}$ cooler in ALB2 than in ALB1 (Fig. 6c).

630 The land surface warming difference between ALB2 and ALB1 is associated 631 with important SLP changes. Globally, SLP is lower in ALB2 compared to ALB1 632 (Fig. 6c). The decrease is relatively weak over ocean $(\sim 1-2 \mathrm{hPa})$, but it is superior to 4 $633 \mathrm{hPa}$ throughout the ME region (with a maximum of $6 \mathrm{hPa}$ at $30^{\circ} \mathrm{N}, 55^{\circ} \mathrm{E}$ ). Over this 634 area, the similarity between SLP and surface temperature differences (Fig. 6c) 635 suggests a direct relation between surface warming and SLP decrease through air 636 density adjustment following the ideal gas law for dry air. This is confirmed by a 637 significant $\left(\mathrm{r}^{2}=0.6\right)$ and negative $\left(-0.5 \mathrm{hPa} /{ }^{\circ} \mathrm{C}\right)$ linear regression between the ME JJAS 638 mean climatological SLP (ALB2-ALB1) difference and the surface temperature 639 (ALB2-ALB1) difference (not shown). Over the rest of the domain, such 
correspondence is less obvious. Over the ME region, SLP bias compared to ERAInterim turns from positive with ALB1 to negative with ALB2 (Fig. 6d), in agreement with the corresponding surface temperature biases and our radiative budget analysis. Overall, the inter-hemispheric SLP gradient and SLP land-sea contrast, which drive the monsoon, are both enhanced in ALB2 compared to ALB1.

In agreement with this improved SLP pattern over the ME region, precipitation over the Indian subcontinent is significantly increased between ALB2 and ALB1 with maxima located along the Western Ghats and the Himalayan foothills (Fig. 6e). The dry bias is also well attenuated over India southward of $25^{\circ} \mathrm{N}$ (Fig. 6f). On the contrary, precipitation is decreased in the equatorial Indian Ocean, over SouthEast Asia and, especially, over South China Sea, even though a wet bias persists in this region. This is the signature of a more northward and continental position of the ITCZ in ALB2 than in ALB1. As a consequence, rainfall pattern and intensity are globally improved in ALB2 (even if significant biases persist). The spatial matching between the increased precipitation over land (Fig. 6e) and the land surface cooling (Fig. 6c) suggests that the warm bias reduction is a consequence of the enhanced rainfall in those regions.

The low-level wind pattern is also clearly improved in ALB2 compared to ALB1 with both a strengthening and a more poleward extension of the Findlater jet and a zonal wind decrease in the eastern part of the BoB and South China Sea. More moisture is advected from the $\mathrm{BoB}$ into Bangladesh and the plains of northern India in ALB2, and the rainfall is enhanced over these areas in ALB2 compared to ALB1 (Fig. 6e). These patterns of differences are again in agreement with a more northward propagation of the monsoon in ALB2 compared to ALB1.

\subsection{LST-SLP-wind relationship}

In order to understand the differences between ALB2 and ALB1, we can assume that the $850 \mathrm{hPa}$ wind is approximatively in geostrophic equilibrium with the SLP outside the equatorial or elevated regions and above the boundary layer where frictional effects are important. This relationship between low-level wind and SLP is well illustrated in Figures 2a and d, in which the Findlater jet closely follows SLP contours and its speed is maximum where the SLP gradient formed between the 
western equatorial $\mathrm{IO}$ and the $\mathrm{ME}$ region is also maximum. A similar relationship can be observed in the BoB with the SLP gradient formed between northern India (e.g. the monsoon trough) and the eastern equatorial IO, and the low-level wind pattern over the eastern IO (north of the equator).

An important implication is that SLP biases can be a major source of errors for the simulated $850 \mathrm{hPa}$ wind pattern over the IO, which brings the moisture over India during monsoon. This is clearly the case in ALB1 simulation: a positive SLP bias over the ME region weakens the SLP gradient over the AS and the Findlater jet, while a negative SLP bias over the monsoon trough region enhances the SLP gradient over the southern BoB and, hence, the $850 \mathrm{hPa}$ zonal wind in this same region, carrying away the moisture from the BoB further eastward (Figs 2c-f).

In addition, SLP biases in our model are directly related to surface temperature biases over land, which, in turn, are related to albedo errors as demonstrated above. Following the ideal gas law, an air temperature increase (decrease) is associated with an air density decrease (increase), which reduces (rises) the SLP. Consequently, LST biases drive errors in the pattern of SLP gradient between land and ocean, which have a direct consequence on the simulated low-level circulation over the ocean. This link between LST, SLP and $850 \mathrm{hPa}$ wind explains most of the differences in the monsoon flow pattern over the ocean between ALB2 and ALB1 (Fig. 8). Over the AS, where the SLP gradient is stronger in ALB2 than in ALB1, stronger and shifted (northward) $850 \mathrm{hPa}$ wind are also found. Conversely, over the eastern IO and the South China Sea, the weaker SLP gradient in ALB2 compared to ALB1 induces a weaker and less zonal monsoon flow over these regions. The positive SLP gradient and $850 \mathrm{hPa}$ wind differences observed over the northern AS, northern BoB and China Sea are the signature of a greater northward extension of the monsoon flow in ALB2 than in ALB1. As it turns more northward, the monsoon flow reaches the Himalaya foothills where it brings more orographic precipitation (Fig. 6e). On the contrary, precipitation is decreased over South-East Asia and South China Sea where the wind is reduced.

\subsection{Albedo effect on the ISM seasonal evolution}

The temporal ISM evolution is also modified by the albedo change from ALB1 to ALB2. Figure 9 shows the annual cycle of SLP gradient between the ME 
region and a western equatorial $\mathrm{IO}$ box $\left(60^{\circ}-80^{\circ} \mathrm{E} / 5^{\circ} \mathrm{S}-5^{\circ} \mathrm{N}\right)$, the $850 \mathrm{hPa}$ wind speed annual cycle over the AS $\left(40^{\circ}-75^{\circ} \mathrm{E} / 0-26^{\circ} \mathrm{N}\right)$ and precipitation over the monsoon core region $\left(65^{\circ}-100^{\circ} \mathrm{E} / 5^{\circ}-30^{\circ} \mathrm{N}\right)$.

The SLP gradient is positive during winter (from November to February), then turns negative during summer corresponding to the monsoon onset and the seasonal reversal of the Findlater jet (Fig. 9a). Interestingly, there is almost no difference between ALB1 and ALB2 during boreal winter. Subsequently, the SLP gradient grows faster in ALB2 than in ALB1 consistent with the seasonal increase of solar radiation over the northern part of the domain from March to June. Consequently, a 1month time lag progressively builds up between the simulated SLP gradient in the two simulations. The difference reaches its maximum in July during the monsoon peak. The SLP gradient in ALB2 is also in much better agreement with the corresponding estimates from ERA-interim.

Furthermore, the seasonal variability of SLP gradient is mainly driven by the low SLP over land because the SLP over the equatorial IO remains relatively steady along the year (not shown; see also Li and Yanai 1996). So the ALB2-ALB1 SLP gradient differences originate mainly from the SLP differences over the ME region, and ultimately, from the LST differences.

This time lag between ALB1 and ALB2 directly impacts the wind reversal timing over the AS and the strengthening of the Findlater jet during the monsoon (Fig. 9b). The monsoon flow begins about one month earlier in the ALB2 simulation compared to ALB1 and its time evolution is in better agreement with ERA-Interim reanalysis. The peak wind speed is also stronger in ALB2 than in ALB1, by about 3 $\mathrm{m} . \mathrm{s}^{-1}$. The maximum wind intensity reached during July in ALB2 is even greater than in ERA-Interim due to a positive wind bias between the equator and $10^{\circ} \mathrm{N}$ (Fig. 6f). The earlier and stronger monsoon onset in the AS directly influences precipitation over India and the BoB (Figs. 9c-d). Precipitation increases more rapidly in ALB2 and its seasonal cycle is consistent with TRMM observations over land: whereas the rainfall maximum is delayed by about two months in ALB1, its timing and magnitude is much better captured in ALB2 simulation. Finally, the continental dry bias is also well attenuated in ALB2, throughout the monsoon season (Fig. 9d). 
In the previous sections, we have shown that land surface properties and resolution appear as two major sources of improvement in our model. However, several questions arise from these results. Is the reduction of monsoon biases

740 observed at higher resolution in the forced HIRES simulation robust in a coupled 741 ocean-atmosphere simulation? Is the albedo influence on the ISM the same at $0.75^{\circ}$ 742 and $0.25^{\circ}$ resolutions? And, finally, are the high-resolution and albedo positive effects 743 on the ISM simulation additive? To address these questions, we carried out two $0.25^{\circ}$ 744 resolution 20-years coupled simulations using, respectively, ALB1 and ALB2 albedo 745 (ALB1HR and ALB2HR, respectively; see Section 2 and Table 2 for details).

The benefit of increasing the horizontal resolution can be assessed by comparing ALB1 and ALB1HR simulations (Figs 10a-b). ALB1HR surface 748 temperature is globally colder than ALB1, except in the western Tibetan plateau 749 where a strong warming is observed $\left(5\right.$ to $\left.10^{\circ} \mathrm{C}\right)$. This warming is again related to the 750 snow cover, which has a reduced spatial extension in ALB1HR compared to ALB1 751 (not shown). This change in the snow cover is directly related to the better representation of the orography at $0.25^{\circ}$ resolution, which allows to represent separately the Himalayan mountain range and the Tibetan plateau. At $0.75^{\circ}$ resolution, such distinction is not possible, which induces important errors in the snow cover and, consequently, in the surface temperature. A wide region extending from central India to north of the BoB and the Himalayan foothills is colder in ALB1HR than in ALB1. This surface cooling ranging from 2 to $6^{\circ} \mathrm{C}$ is directly related to the increased precipitation in the same regions (Fig. 10b). A significant rainfall increase is also observed at $0.25^{\circ}$ resolution in regions of strong orographic forcing. On the contrary, precipitation is decreased over South China Sea and over the Maritime

761 Continent region. Interestingly, no significant change is observed in the large-scale 762 monsoon circulation (Fig. 10b), which suggests that the rainfall differences between 763 ALB1HR and ALB1 are mainly related to local changes and not to large-scale 764 environment modifications. A similar statement can be made by comparing the FORC 765 and HIRES simulations described in Section 3.2.

The sensitivity of the simulated ISM to the land surface albedo is very similar 767 at $0.75^{\circ}$ resolution (ALB2-ALB1) and $0.25^{\circ}$ resolution (ALB2HR-ALB1HR) as 768 shown in Figs. 6c-e and 10c-d, respectively. A large land surface warming and SLP 

decrease, directly related to the albedo change, are observed over the ME region and the western part of the Tibetan plateau at both resolutions. The warming is roughly the same at both resolutions, except in some localized places of the Tibetan plateau, where the warming is greater at $0.75^{\circ}$ resolution. On the other hand, the surface cooling observed at $0.75^{\circ}$ resolution over southern India, Bangladesh and China is well attenuated at $0.25^{\circ}$ resolution, where it only reaches $1^{\circ} \mathrm{C}$ locally. Concerning the precipitation over land, the change due to albedo shows a similar impact at both resolutions, even if the rainfall increase is more concentrated along the western Ghats and the Himalaya foothills at $0.25^{\circ}$ resolution (Fig. 10d). Contrarily to the resolution increase, albedo change induces a large-scale strengthening of the simulated ISM flow, which brings more humidity, and hence more precipitation, over land. This mechanism appears to be robust at the two different resolutions we considered (e.g. 0.75 and $0.25^{\circ}$ ).

Finally, Figures 10e-f show that the benefits from high-resolution and modified land surface albedo are clearly cumulative in terms of surface temperature and precipitation biases. The net and significant result is a warming of the ME region and the western Tibetan plateau and a cooling over continental India and Bangladesh. Precipitation is significantly increased along the Ghats, the Himalayan foothills, the Myanmar mountains and -though to a lesser extent- over continental India. The lowlevel circulation strengthening and northward migration of the ITCZ are almost entirely related to the albedo change as increasing the horizontal resolution does not significantly modify the $850 \mathrm{hPa}$ wind pattern (Fig. 10b). The combination of modified albedo with high resolution significantly reduce ISM biases (see Fig. 10g-h), but a significant (limited) warm (dry) bias persists over India. A wet bias also persists over South-East Asia and the South China Sea, which is related to a too strong lowlevel wind circulation over the same region and the BoB. Those biases are directly related to the warm temperature and low SLP biases over India.

\title{
5. Conclusion and Perspectives
}

\author{
5.1. Summary
}


The present study revisits the mechanism originally presented by Charney et 801 al. (1977) linking land surface albedo, surface heating and the ISM characteristics in a 802 state-of-the-art general circulation model extending between $45^{\circ} \mathrm{S}$ and $45^{\circ} \mathrm{N}$. More 803 precisely, we demonstrate that constraining land surface heating by using observed 804 albedo climatology leads to significant improvements in ISM simulation with our 805 model, especially in terms of the ISM rainfall onset and climatology. Moreover, we 806 illustrate that our results are valid in both coupled and forced frameworks, at two 807 spatial resolutions $\left(0.75\right.$ and $\left.0.25^{\circ}\right)$ and with two albedo datasets (AVHRR and 808 MODIS), hereby highlighting the robustness of our findings. These results emphasize the important role of the non-elevated land surface 810 heating pattern on the ISM: the Middle-East area appears as a key region, which 811 exerts a strong control on the meridional migration on the ITCZ through its warming 812 pattern and amplitude. This is consistent with results from Boos and Kuang (2013), 813 suggesting that the monsoon responds significantly to surface heat fluxes associated 814 with temperature maxima. The mechanism proposed in our study to explain the ISM 815 biases is different from the Tibetan plateau theory described by Li and Yanai (1996), 816 in which the sensible heat flux from this high-elevated surface directly contributes to 817 the reversal of the meridional temperature gradient. Here, the land surface heating 818 locally lowers the surface pressure, which modifies the large-scale pressure gradient 819 between the ME region and the western equatorial IO. The low-level circulation 820 adjusts to these changes in the SLP gradient and directly affects the humidity 821 transport necessary for improving continental precipitation in our simulations. 822 Concretely, the JJAS Indian land dry bias, which is about $46 \%(-3.6 \mathrm{~mm} /$ day $)$ in 823 ALB1 compared to TRMM (7.9 mm/day), is reduced to $18 \%$ (-1.4 mm/day) in ALB2. 824 The ISM duration in ALB2 is also extended by 1 month in agreement with TRMM 825 observations. This suggests that surface heating may play an important role in 826 modulating the ISM biases, even though the deep low over the ME region cannot be 827 purely considered as a "heat" low, as demonstrated by Bollasina and Nigam (2011). Another important implication of this result is that any significant LST bias 829 over the northern plains of India can generate errors in the representation of the 830 monsoon trough, through the mechanism discussed above. This is clearly the case 831 with the warm temperature and low SLP biases over India, which strengthen the 832 pressure gradient between India and the eastern equatorial IO. The associated zonal 
wind intensification brings too much rainfall to South-East Asia and South China Sea, instead of feeding the monsoon trough region.

Horizontal resolution also appears as a key parameter to improve the ISM representation in both forced and coupled configurations of our model. Precisely, the JJAS Indian land dry bias is reduced by $31 \%(+1.3 \mathrm{~mm} /$ day $)$ between ALB1 (4.3 $\mathrm{mm} /$ day $)$ and ALB1HR (5.6 mm/day) and by $11 \%(+0.7 \mathrm{~mm} /$ day $)$ between ALB2 $(6.5$ $\mathrm{mm} /$ day $)$ and ALB2HR (7.2 $\mathrm{mm} /$ day). Increasing the horizontal resolution also improves the rainfall pattern correlation over the Indian region from 0.5 to 0.7 with both ALB1 and ALB2 albedos. The absence of modification in the low-level circulation between ALB1 and ALB1HR also suggests that a $0.75^{\circ}$ resolution is fine enough to resolve the main orographic features necessary to prevent the ventilation mechanism with cold and dry air from high latitudes described by Chakraborty et al.

$845(2002,2006)$ and by Boos and Kuang (2010). On the contrary, the absence of large846 scale atmospheric response to the strong warming observed in the western Tibetan 847 plateau supports the idea that the Tibetan plateau is not a dominant source of heating 848 for the ISM. Nonetheless, supplementary experiments following Boos and Kuang 849 (2010, 2013) and Ma et al. (2014) methodology would be necessary to precisely 850 assess the respective roles of the Himalayan mountains and Tibetan plateau heating 851 effects in our model.

\subsection{Perspectives}

Understanding the development of the Indian warm LST bias over the Indo-

855 Gangetic plains during boreal spring and its maintenance during the monsoon season 856 is of critical importance for future ISM studies. Furthermore, an important number of 857 CGCMs suffer from the same caveats as recently illustrated by the CMIP5 ensemble 858 mean (Sooraj et al. 2015). Consequently, these models could also benefit from 859 substantial improvements in terms of monsoon representation if the Indian warm LST 860 bias was successfully understood and corrected.

861 Various promising directions can be followed to improve LST and rainfall 862 over continental India in current state-of-the-art climate models. Concerning 863 specifically the WRF-NOAH LSM model, a necessary step would be the 864 implementation of a complete land surface albedo parameterization, such as in 
865 NCEP/GFS (Hou et al. 2002), NCAR/CAM (Bonan et al. 2002) and ECHAM6

866 (Brovkin et al. 2013) models. This would allow a more realistic computation of the

867 surface SW fluxes, and consequently an additional LST bias reduction. Other domains

868 of improvement concern the representation of soil characteristics and irrigation in the

869 land surface models (Saeed et al. 2009; Kumar et al. 2014), convection

870 parameterization (Ganai et al. 2015) or further horizontal grid refinement (Sabin et al.

871 2013) to correctly capture all the important processes, which contribute to ISM

872 rainfall. Furthermore, the impact of SST biases on ISM in remote regions and not only

873 in the IO must be also properly evaluated in a coupled framework (Prodhomme et al.

874 2015). Concerning RCMs, our study emphasizes the importance of including the ME

875 region in the model domain when simulating the ISM in order to correctly represent

876 the large-scale land-sea pressure gradient which drives the low-level monsoon flow.

877 Finally, due to the large diversity of the albedo estimation in current CGCMs

878 and RCMs (Wang et al. 2007), similar experiments with other models are clearly

879 needed to demonstrate that the results presented here are robust and may lead to

880 improvements in our capability to predict the monsoon at different time scales or to

881 assess the future of the monsoon in a global warming context. Such improvements of

882 monsoon simulations are of utmost importance for the society and the livelihood of

883 the population in South Asia (Annamalai et al. 2015; Sabeerali et al. 2015; Wang et

884 al. 2015).

885 
This work was founded by the PULSATION ANR-11-MONU-0010 project of 888 the French National Research Agency (ANR) and the European Commission's 7th 889 Framework Program, under Grant Agreement number 282672, EMBRACE project. 890 Partial support (P. Terray) given by the Earth System Science Organization, Ministry 891 of Earth Sciences, Government of India (Project no MM/SERP/CNRS/2013/INT892 10/002) is also acknowledged.

893 Simulations were performed on the Curie supercomputer, owned by GENCI 894 and operated into the TGCC by CEA. We acknowledge PRACE for awarding us 895 access to the Curie supercomputer thought its 3rd, 5th and 9th calls. WRF-ARW was 896 provided by the University Corporation for Atmospheric Research. 
Abhik S, Mukhopadhyay P, Goswami BN (2014) Evaluation of mean and intraseasonal variability of Indian summer monsoon simulation in ECHAM5: identification of possible source of bias. Clim Dyn 43:389-406. doi: 10.1007/s00382-013-1824-7

Annamalai H, Taguchi B, Sperber KR, et al (2015) Persistence of Systematic errors in the Asian-Australian monsoon Precipitation in climate models: a way forward.

Axell LB (2002) Wind-driven internal waves and Langmuir circulations in a numerical ocean model of the southern Baltic Sea. J Geophys Res 107:3204. doi: 10.1029/2001JC000922

Barnier B, LeSommer J, Molines J-M, et al (2007) Eddy-permitting ocean circulation hindcasts of the past decades. CLIVAR Exch 8-10.

Betts a. K, Miller MJ (1986) A new convective adjustment scheme. Part II: Single column tests using GATE wave, BOMEX, ATEX and arctic air-mass data sets. Q J R Meteorol Soc 112:693-709. doi: 10.1002/qj.49711247308

Blanke B, Delecluse P (1993) Variability of the Tropical Atlantic Ocean Simulated by a General Circulation Model with Two Different Mixed-Layer Physics. J Phys Oceanogr 23:1363-1388. doi: 10.1175/15200485(1993)023<1363:VOTTAO $>2.0 . C O ; 2$

Bollasina M a., Ming Y (2013) The general circulation model precipitation bias over the southwestern equatorial Indian Ocean and its implications for simulating the South Asian monsoon. Clim Dyn 40:823-838. doi: 10.1007/s00382-012-1347-7

Bollasina M, Nigam S (2011) The summertime "heat" low over Pakistan/northwestern India: evolution and origin. Clim Dyn 37:957-970. doi: 10.1007/s00382-010-0879-y

Bonan GB, Oleson KW, Vertenstein M, et al (2002) The Land Surface Climatology of the Community Land Model Coupled to the NCAR Community Climate Model*. J Clim 15:3123-3149. doi: 10.1175/15200442(2002)015<3123:TLSCOT $>2.0$. CO;2

Boos WR (Yale) (2015) A review of recent progress on Tibet's role in the South Asian monsoon.

Boos WR, Hurley J V. (2013) Thermodynamic Bias in the Multimodel Mean Boreal Summer Monsoon*. J Clim 26:2279-2287. doi: 10.1175/JCLI-D-12-00493.1

Boos WR, Kuang Z (2013) Sensitivity of the South Asian monsoon to elevated and non-elevated heating. Sci Rep 3:1192. doi: 10.1038/srep01192

Boos WR, Kuang Z (2010) Dominant control of the South Asian monsoon by orographic insulation versus plateau heating. Nature 463:218-222. doi: 10.1038/nature08707

Brovkin V, Boysen L, Raddatz T, et al (2013) Evaluation of vegetation cover and land-surface albedo in MPI-ESM CMIP5 simulations. J Adv Model Earth Syst 5:48-57. doi: 10.1029/2012MS000169

Burchard H (2002) Energy-conserving discretisation of turbulent shear and buoyancy production. Ocean Model 4:347-361. doi: 10.1016/S1463-5003(02)00009-4 
Chakraborty A. (2002) Role of Asian and African orography in Indian summer monsoon. Geophys Res Lett 29:1989. doi: 10.1029/2002GL015522

Chakraborty A, Nanjundiah RS, Srinivasan J (2006) Theoretical aspects of the onset of Indian summer monsoon from perturbed orography simulations in a GCM. Ann Geophys 24:2075-2089. doi: 10.5194/angeo-24-2075-2006

Charney J, Quirk WJ, Chow S, Kornfield J (1977) A Comparative Study of the Effects of Albedo Change on Drought in Semi-Arid Regions. J Atmos Sci 34:1366-1385. doi: 10.1175/1520-0469(1977)034<1366:ACSOTE >2.0.CO;2

Chen F, Dudhia J (2001) Coupling an Advanced Land Surface-Hydrology Model with the Penn State-NCAR MM5 Modeling System. Part II: Preliminary Model Validation. Mon Weather Rev 129:587-604. doi: 10.1175/15200493(2001)129<0587:CAALSH $>2.0 . \mathrm{CO} ; 2$

Cherchi A, Navarra A (2006) Sensitivity of the Asian summer monsoon to the horizontal resolution: differences between AMIP-type and coupled model experiments. Clim Dyn 28:273-290. doi: 10.1007/s00382-006-0183-Z

Chou C (2003) Land?sea heating contrast in an idealized Asian summer monsoon. Clim Dyn 21:11-25. doi: 10.1007/s00382-003-0315-7

Chou M-D, Suarez MJ (1999) A Solar Radiation Parameterization for Atmospheric Studies. NASA Tech Rep 15:TM-1999-104606.

Christensen JH, Hewitson B (2007) Regional climate projections. In: Climate Change 2007: The Physical Science Basis. Contribution of Working Group I to the Fourth Assessment Report of the Intergovernmental Panel on Climate Change. $p$ 940

Crétat J, Masson S, Berthet S, et al (2016) Control of shortwave radiation parameterization on tropical climate SST-forced simulation. Clim Dyn 1-20. doi: 10.1007/s00382-015-2934-1

Csiszar I, Gutman G (1999) Mapping global land surface albedo from NOAA AVHRR. J Geophys Res 104:6215. doi: 10.1029/1998JD200090

Dai A, Li H, Sun Y, et al (2013) The relative roles of upper and lower tropospheric thermal contrasts and tropical influences in driving Asian summer monsoons. J Geophys Res Atmos 118:7024-7045. doi: 10.1002/jgrd.50565

Dash SK, Pattnayak KC, Panda SK, et al (2014) Impact of domain size on the simulation of Indian summer monsoon in RegCM4 using mixed convection scheme and driven by HadGEM2. Clim Dyn 44:961-975. doi: 10.1007/s00382014-2420-1

De Boyer Montégut C, Vialard J, Shenoi SSC, et al (2007) Simulated Seasonal and Interannual Variability of the Mixed Layer Heat Budget in the Northern Indian Ocean*. J Clim 20:3249-3268. doi: 10.1175/JCLI4148.1

Dee DP, Uppala SM, Simmons a. J, et al (2011) The ERA-Interim reanalysis: Configuration and performance of the data assimilation system. Q J R Meteorol Soc 137:553-597. doi: 10.1002/qj.828

Dudhia J (1989) Numerical Study of Convection Observed during the Winter Monsoon Experiment Using a Mesoscale Two-Dimensional Model. J. Atmos. Sci. 46:3077-3107. 
Evan S, Alexander MJ, Dudhia J (2012) Model study of intermediate-scale tropical inertia-gravity waves and comparison to TWP-ICE campaign observations. J Atm Sci 69:591-610

Flaounas E, Janicot S, Bastin S, Roca R (2012) The West African monsoon onset in 2006: sensitivity to surface albedo, orography, SST and synoptic scale dry-air intrusions using WRF. Clim Dyn 38:685-708. doi: 10.1007/s00382-011-1255-2

Flohn H (1968) Contributions to a Meteorology of the Tibetan Highlands. Department of Atmospheric Science, Colorado State University Fort Collins, Colorado

Friedl M., McIver D., Hodges JC., et al (2002) Global land cover mapping from MODIS: algorithms and early results. Remote Sens Environ 83:287-302. doi: 10.1016/S0034-4257(02)00078-0

Gadgil S, Joseph P V., Joshi N V. (1984) Ocean-atmosphere coupling over monsoon regions. Nature 312:141-143. doi: 10.1038/312141a0

Ganai M, Mukhopadhyay P, Krishna RPM, Mahakur M (2015) The impact of revised simplified Arakawa-Schubert convection parameterization scheme in CFSv2 on the simulation of the Indian summer monsoon. Clim Dyn 45:881-902. doi: $10.1007 / \mathrm{s} 00382-014-2320-4$

Gent PR, Mcwilliams JC (1990) Isopycnal Mixing in Ocean Circulation Models. J Phys Oceanogr 20:150-155. doi: 10.1175/15200485(1990)020<0150:IMIOCM $>2.0$. CO;2

Goswami BB, Deshpande M, Mukhopadhyay P, et al (2014) Simulation of monsoon intraseasonal variability in NCEP CFSv2 and its role on systematic bias. Clim Dyn 43:2725-2745. doi: 10.1007/s00382-014-2089-5

Gutman G, Ignatov a. (1998) The derivation of the green vegetation fraction from NOAA/AVHRR data for use in numerical weather prediction models. Int. J. Remote Sens. 19:1533-1543.

Hagos S, Leung R, Rauscher SA, Ringler T (2013) Error Characteristics of Two Grid Refinement Approaches in Aquaplanet Simulations: MPAS-A and WRF. Mon Weather Rev 141:3022-3036. doi: 10.1175/MWR-D-12-00338.1

He H, Sui C-H, Jian M, et al (2003) The Evolution of Tropospheric Temperature Field and its Relationship with the Onset of Asian Summer Monsoon. J Meteorol Soc Japan 81:1201-1223. doi: 10.2151/jmsj.81.1201

Hong S, Lim J (2006) The WRF single-moment 6-class microphysics scheme (WSM6). J Korean Meteorol Soc 42:129-151.

Hong S-Y, Noh Y, Dudhia J (2006) A New Vertical Diffusion Package with an Explicit Treatment of Entrainment Processes. Mon Weather Rev 134:2318-2341. doi: 10.1175/MWR3199.1

Hou YT, Moorthi S, Campana K a (2002) Parameterization of solar radiation transfer in the NCEP models. NCEP Off note 441:1-46.

Huffman GJ, Adler RF, Bolvin DT, Nelkin EJ (2010) The TRMM Multi-Satellite Precipitation Analysis (TMPA). Satell Rainfall Appl Surf Hydrol 3-22. doi: 10.1007/978-90-481-2915-7_1 
Janjić ZI (1994) The Step-Mountain Eta Coordinate Model: Further Developments of the Convection, Viscous Sublayer, and Turbulence Closure Schemes. Mon. Weather Rev. 122:927-945.

Jin,Y., C. B. Schaaf, C. E.Woodcock, F. Gao, X. Li, A. H. Strahler,W. Lucht, and S. Liang (2003) Consistency of MODIS surface bidirectional reflectance distribution function and albedo retrievals, 2. Validation, J. Geophys. Res., 108(D5), 4159, doi:10.1029/2002JD002804

Joseph S, Sahai a. K, Goswami BN, et al (2012) Possible role of warm SST bias in the simulation of boreal summer monsoon in SINTEX-F2 coupled model. Clim Dyn 38:1561-1576. doi: 10.1007/s00382-011-1264-1

Kain JS (2004) The Kain-Fritsch Convective Parameterization: An Update. J Appl Meteorol 43:170-181. doi: 10.1175/15200450(2004)043<0170:TKCPAU >2.0.CO;2

Kato S, Loeb NG, Rose FG, et al (2013) Surface Irradiances Consistent with CERESDerived Top-of-Atmosphere Shortwave and Longwave Irradiances. J Clim 26:2719-2740. doi: 10.1175/JCLI-D-12-00436.1

Kelly P, Mapes B (2010) Land Surface Heating and the North American Monsoon Anticyclone: Model Evaluation from Diurnal to Seasonal. J Clim 23:4096-4106. doi: 10.1175/2010JCLI3332.1

Kelly P, Mapes B (2013) Asian Monsoon Forcing of Subtropical Easterlies in the Community Atmosphere Model: Summer Climate Implications for the Western Atlantic. J Clim 26:2741-2755. doi: 10.1175/JCLI-D-12-00339.1

Krishnamurthy V, Ajayamohan RS (2010) Composite Structure of Monsoon Low Pressure Systems and Its Relation to Indian Rainfall. J Clim 23:4285-4305. doi: 10.1175/2010JCLI2953.1

Kumar P, Podzun** R, Hagemann S, Jacob D (2014) Impact of modified soil thermal characteristic on the simulated monsoon climate over south Asia. J Earth Syst Sci 123:151-160. doi: 10.1007/s12040-013-0381-0

Leduc M, Laprise R (2009) Regional climate model sensitivity to domain size. Clim Dyn 32:833-854. doi: 10.1007/s00382-008-0400-z

Levine RC, Turner AG (2012) Dependence of Indian monsoon rainfall on moisture fluxes across the Arabian Sea and the impact of coupled model sea surface temperature biases. Clim Dyn 38:2167-2190. doi: 10.1007/s00382-011-1096-Z

Lévy M, Estublier A, Madec G (2001) Choice of an advection scheme for biogeochemical models. Geophys Res Lett 28:3725-3728. doi: 10.1029/2001GL012947

Li C, Yanai M (1996) The Onset and Interannual Variability of the Asian Summer Monsoon in Relation to Land-Sea Thermal Contrast. J. Clim. 9:358-375.

Li G, Xie S-P, Du Y (2015) Monsoon-Induced Biases of Climate Models over the Tropical Indian Ocean*. J Clim 28:3058-3072. doi: 10.1175/JCLI-D-14-00740.1

Lucas-Picher P, Christensen JH, Saeed F, et al (2011) Can Regional Climate Models Represent the Indian Monsoon? J Hydrometeorol 12:849-868. doi: 10.1175/2011JHM1327.1 
Ma D, Boos W, Kuang Z (2014) Effects of Orography and Surface Heat Fluxes on the South Asian Summer Monsoon. J Clim 27:6647-6659. doi: 10.1175/JCLI-D-1400138.1

Madec G (2008) NEMO ocean engine. Inst. Pierre-Simon Laplace, Paris, France

Masson S, Terray P, Madec G, et al (2012) Impact of intra-daily SST variability on ENSO characteristics in a coupled model. Clim Dyn 39:681-707. doi: $10.1007 / \mathrm{s} 00382-011-1247-2$

Meehl G a (1994) Influence of the Land Surface in the Asian Summer Monsoon: External Conditions versus Internal Feedbacks. J. Clim. 7:1033-1049.

Mellor G, Blumberg A (2004) Wave Breaking and Ocean Surface Layer Thermal Response. J Phys Oceanogr 34:693-698. doi: 10.1175/2517.1

Mlawer EJ, Taubman SJ, Brown PD, et al (1997) Radiative transfer for inhomogeneous atmospheres: RRTM, a validated correlated-k model for the longwave. J Geophys Res 102:16663. doi: 10.1029/97JD00237

Molnar P, Boos WR, Battisti DS (2010) Orographic Controls on Climate and Paleoclimate of Asia: Thermal and Mechanical Roles for the Tibetan Plateau. Annu Rev Earth Planet Sci 38:77-102. doi: 10.1146/annurev-earth-040809152456

Mukhopadhyay P, Taraphdar S, Goswami BN, Krishnakumar K (2010) Indian Summer Monsoon Precipitation Climatology in a High-Resolution Regional Climate Model: Impacts of Convective Parameterization on Systematic Biases. Weather Forecast 25:369-387. doi: 10.1175/2009WAF2222320.1

P Sabin T, Krishnan R, Ghattas J, et al (2013) High resolution simulation of the South Asian monsoon using a variable resolution global climate model. Clim Dyn 41:173-194. doi: 10.1007/s00382-012-1658-8

Pattnaik S, Abhilash S, De S, et al (2013) Influence of convective parameterization on the systematic errors of Climate Forecast System (CFS) model over the Indian monsoon region from an extended range forecast perspective. Clim Dyn 41:341365. doi: $10.1007 / \mathrm{s} 00382-013-1662-7$

Prodhomme C, Terray P, Masson S, et al (2015) Oceanic factors controlling the Indian summer monsoon onset in a coupled model. Clim Dyn 44:977-1002. doi: 10.1007/s00382-014-2200-y

Prodhomme C, Terray P, Masson S, et al (2014) Impacts of Indian Ocean SST biases on the Indian Monsoon: as simulated in a global coupled model. Clim Dyn 42:271-290. doi: 10.1007/s00382-013-1671-6

Rajagopalan B, Molnar P (2013) Signatures of Tibetan Plateau heating on Indian summer monsoon rainfall variability. J Geophys Res Atmos 118:1170-1178. doi: $10.1002 /$ jgrd. 50124

Ray P, Zhang C, Moncrieff MW, Dudhia J, Caron JM, Leung LR, Bruyère C (2011) Role of the atmospheric mean state on the initiation of the Madden-Julian oscillation in a tropical channel model. Clim Dyn 36:161-184

Rechid D, Raddatz TJ, Jacob D (2009) Parameterization of snow-free land surface albedo as a function of vegetation phenology based on MODIS data and applied 

in climate modelling. Theor Appl Climatol 95:245-255. doi: 10.1007/s00704008-0003-y

Reynolds RW, Smith TM, Liu C, et al (2007) Daily High-Resolution-Blended Analyses for Sea Surface Temperature. J Clim 20:5473-5496. doi: 10.1175/2007JCLI1824.1

Rodwell MJ, Hoskins BJ (1996) Monsoons and the dynamics of deserts. Q J R Meteorol Soc 122:1385-1404. doi: 10.1002/qj.49712253408

Sabeerali CT, Ramu Dandi a., Dhakate A, et al (2013) Simulation of boreal summer intraseasonal oscillations in the latest CMIP5 coupled GCMs. J Geophys Res Atmos 118:4401-4420. doi: 10.1002/jgrd.50403

Sabeerali CT, Rao S a., Dhakate a. R, et al (2015) Why ensemble mean projection of south Asian monsoon rainfall by CMIP5 models is not reliable? Clim Dyn 45:161-174. doi: 10.1007/s00382-014-2269-3

Saeed F, Hagemann S, Jacob D (2009) Impact of irrigation on the South Asian summer monsoon. Geophys Res Lett 36:L20711. doi: 10.1029/2009GL040625

Saha SK, Pokhrel S, Chaudhari HS, et al (2014) Improved simulation of Indian summer monsoon in latest NCEP climate forecast system free run. Int J Climatol 34:1628-1641. doi: 10.1002/joc.3791

Samala BK, C N, Banerjee S, et al (2013) Study of the Indian summer monsoon using WRF-ROMS regional coupled model simulations. Atmos Sci Lett 14:20-27. doi: 10.1002/as 12.409

Samson G, Masson S, Lengaigne M, et al (2014) The NOW regional coupled model: Application to the tropical Indian Ocean climate and tropical cyclone activity. J Adv Model Earth Syst 6:700-722. doi: 10.1002/2014MS000324

Schaaf CB, Liu J, Gao F, Strahler AH (2011) Land Remote Sensing and Global Environmental Change. L Remote Sens Glob Environ Chang 11:549-561. doi: 10.1007/978-1-4419-6749-7

Seo H, Xie S-P, Murtugudde R, et al (2009) Seasonal Effects of Indian Ocean Freshwater Forcing in a Regional Coupled Model. J Clim 22:6577-6596. doi: 10.1175/2009JCLI2990.1

Skamarock WC, Klemp JB (2008) A time-split nonhydrostatic atmospheric model for weather research and forecasting applications. J Comput Phys 227:3465-3485. doi: 10.1016/j.jcp.2007.01.037

Sooraj KP, Terray P, Mujumdar M (2015) Global warming and the weakening of the Asian summer monsoon circulation: assessments from the CMIP5 models. Clim Dyn 45:233-252. doi: 10.1007/s00382-014-2257-7

Sperber KR, Annamalai H, Kang I-S, et al (2013) The Asian summer monsoon: an intercomparison of CMIP5 vs. CMIP3 simulations of the late 20th century. Clim Dyn 41:2711-2744. doi: 10.1007/s00382-012-1607-6

Srinivas C V., Hariprasad D, Bhaskar Rao D V., et al (2013) Simulation of the Indian summer monsoon regional climate using advanced research WRF model. Int $\mathrm{J}$ Climatol 33:1195-1210. doi: 10.1002/joc.3505 
Terray P, Kamala K, Masson S, et al (2012) The role of the intra-daily SST variability in the Indian monsoon variability and monsoon-ENSO-IOD relationships in a global coupled model. Clim Dyn 39:729-754. doi: 10.1007/s00382-011-1240-9

Treguier a. M, Held IM, Larichev VD (1997) Parameterization of Quasigeostrophic Eddies in Primitive Equation Ocean Models. J Phys Oceanogr 27:567-580. doi: 10.1175/1520-0485(1997)027<0567:POQEIP >2.0.CO;2

Ulate M, Zhang C, Dudhia J (2015) Role of water vapor and convection-circulation decoupling in MJO simulations by a tropical channel model. J Adv Model Earth Syst, doi: 10.1002/2014MS000393

Valcke S (2012) The OASIS3 coupler: a European climate modelling community software. Geosci Model Dev Discuss 5:2139-2178. doi: 10.5194/gmdd-5-21392012

Voldoire a., Sanchez-Gomez E, Salas y Mélia D, et al (2013) The CNRM-CM5.1 global climate model: Description and basic evaluation. Clim Dyn 40:20912121. doi: 10.1007/s00382-011-1259-y

Wang B (2006) The Asian monsoon. Springer/Praxis Publishing, New York, 787 pp.

Wang B, Ding Q, Fu X, et al (2005) Fundamental challenge in simulation and prediction of summer monsoon rainfall. Geophys Res Lett 32:2-5. doi: 10.1029/2005GL022734

Wang B, Xiang B, Li J, et al (2015) Rethinking Indian monsoon rainfall prediction in the context of recent global warming. Nat Commun 6:7154. doi: $10.1038 /$ ncomms 8154

Wang, K., J. Liu, X. Zhou, M. Sparrow, M. Ma, Z. Sun, and W. Jiang (2004) Validation of the MODIS global land surface albedo product using ground measurements in a semidesert region on the Tibetan Plateau, J. Geophys. Res., 109, D05107, doi:10.1029/2003JD004229

Wang Z, Zeng X, Barlage M (2007) Moderate Resolution Imaging Spectroradiometer bidirectional reflectance distribution function-based albedo parameterization for weather and climate models. J Geophys Res 112:D02103. doi: 10.1029/2005JD006736

Wu G, Liu Y, He B, et al (2012) Thermal Controls on the Asian Summer Monsoon. Sci Rep 2:1-7. doi: 10.1038/srep00404

Wu GX, Liu Y, Zhu X, et al (2009) Multi-scale forcing and the formation of subtropical desert and monsoon. Ann Geophys 27:3631-3644. doi: 10.5194/angeo-27-3631-2009

Wu YH, Raman S, Mohanty UC, Madala R V (2002) Sensitivity of monsoon circulation and precipitation over India to model horizontal resolution and orographic effects. Meteorol Appl 9:345-356. doi: Doi $10.1017 / \mathrm{S} 1350482702003080$

Xavier PK, Marzin C, Goswami BN (2007) An objective definition of the Indian summer monsoon season and a new perspective on the ENSO-monsoon relationship. Q J R Meteorol Soc 133:749-764. doi: 10.1002/qj.45 
Yanai M, Li C, Song Z (1992) Seasonal Heating of the Tibetan Plateau and Its Effects 1198 1199 on the Evolution of the Asian Summer Monsoon. J Meteorol Soc Japan 70:189221.

1200 Zhaohui L, Qingcun Z (1997) Simulation of east asian summer monsoon by using an 1201 improved AGCM. Adv Atmos Sci 14:513-526. doi: 10.1007/s00376-997-0069-y 1202 


\section{Table Captions}

1204 Table 1: List of the acronyms used.

1205 Table 2: Summary of tropical-channel simulations. Differences between the 1206 simulations configurations are given in the "Setup" column. 
1209 Figure 1. (a) MODIS-IGBP dominant land-use categories. (b) Annual snow-free 1210 black-sky broadband SW land albedo from MODIS product (\%). Note that in all 1211 figures, ocean albedo is not displayed for clarity. (c) Time-average difference between 1212 ALB1 albedo and MODIS snow-free product (\%). (d) Same as (c) for ALB2 (\%).

1213 Figure 2. (a) Summer monsoon (JJAS) mean climatological ERA-Interim surface 1214 temperature $\left({ }^{\circ} \mathrm{C}\right.$, shaded) and SLP ( $\mathrm{hPa}$, contours; contours greater than $1020 \mathrm{hPa}$ are 1215 not drawn for clarity). (b) Same as (a) for ALB1. (c) ALB1 surface temperature $\left({ }^{\circ} \mathrm{C}\right.$, 1216 shaded) and SLP (hPa, contours) biases compared to ERA-Interim (contours bias greater than $\pm 8 \mathrm{hPa}$ are not drawn for clarity). (d) TRMM precipitation ( $\mathrm{mm} /$ day, 1218 shaded) and ERA-Interim $850 \mathrm{hPa}$ wind (m/s, vectors). (e) Same as (d) for ALB1. (f) 1219 Biases of ALB1 precipitation and wind computed as the difference between (b) and 1220 (a).

1221 Figure 3. (a) Rainfall monthly seasonal climatology ( $\mathrm{mm} /$ day) averaged over land 1222 only in the $65^{\circ}-100^{\circ} \mathrm{E} / 5^{\circ}-30^{\circ} \mathrm{N}$ box (see inset map for box limits) for TRMM 1223 observations (black) and for the various numerical simulations (colors); see Table 2 1224 for the description of the experiments. (b) Same as (a), averaged over land and ocean. 1225 The dashed lines show the annual long-term mean of the various climatologies.

1226 Figure 4. (left column) JJAS rainfall $(\mathrm{mm} / \mathrm{d}$, shaded) and $850 \mathrm{hPa}$ wind $(\mathrm{m} / \mathrm{s}$, vectors) 1227 biases of the various sensitivity experiments, compared to TRMM and ERA-Interim 1228 datasets, respectively: (a) FRC, (b) HIRES, (c) CONV and (d) RAD; see Table 2 for 1229 the description of these experiments. (right column) JJAS surface temperature $\left({ }^{\circ} \mathrm{C}\right.$, 1230 shaded) and SLP (hPa, contours) biases compared to ERA-Interim dataset :(a) FRC, 1231 (b) HIRES, (c) CONV and (d) RAD.

1232 Figure 5. (a) Pre-monsoon (MAM) mean climatological ERA-Interim surface 1233 temperature $\left({ }^{\circ} \mathrm{C}\right.$, shaded) and SLP (hPa, contours). (b) Biases of ALB1 surface 1234 temperature and SLP compared to ERA-Interim.

1235 Figure 6. (a) JJAS mean climatological albedo difference between ALB2 and ALB1 1236 (unit \%). (b) ALB2 albedo bias compared to MODIS (unit \%). (c) Surface 1237 temperature $\left({ }^{\circ} \mathrm{C}\right.$, shaded) and SLP (hPa, contours) differences between ALB2 and 1238 ALB1. (d) ALB2 surface temperature $\left({ }^{\circ} \mathrm{C}\right.$, shaded) and SLP (hPa, contours) biases 1239 compared to ERA-Interim. (e) Precipitation (mm/day, shaded) and $850 \mathrm{hPa}$ wind (m/s, 
vectors) differences between ALB2 and ALB1. (f) ALB2 precipitation (mm/day, shaded) and $850 \mathrm{hPa}$ wind (m/s, vectors) biases compared to ERA-Interim.

Figure 7. (a) JJAS mean climatological surface radiative heat fluxes averaged over the "Middle East" region (see inset map for box limits, only the land points in the box are considered). Black, blue and red bars show CERES-EBAF, ALB1 and ALB2 estimates, respectively. The bars from left to right are for downward shortwave (SW_DN), upward shortwave (SW_UP), net shortwave (SW_NET), upward longwave (LW_UP), downward longwave (LW_DN), net longwave (LW NET) and total radiative heat fluxes (SW+LW_NET) at land surface (in $\left.\mathrm{W} / \mathrm{m}^{2}\right)$. (b) same as (a), for ALB1 and ALB2 errors compared to CERES-EBAF dataset.

Figure 8. JJAS mean climatological differences of SLP gradient $(\mathrm{Pa} / \mathrm{km}$, shaded) and $850 \mathrm{hPa}$ wind (m/s, vectors) differences between ALB2 and ALB1 experiments. Land surfaces are masked for clarity.

Figure 9. (a) SLP (hPa) monthly climatological seasonal cycle difference between the Middle-East ("ME") and the Western Equatorial IO ("WIO") regions in ERA-Interim (black), ALB1 (blue) and ALB2 (red). The boxes limits are featured on the inset map. (b) $850 \mathrm{hPa}$ wind $(\mathrm{m} / \mathrm{s})$ 5-days climatological seasonal cycle averaged over the Arabian Sea ("AS", see inset map for box limits). (c) Rainfall (mm/day) 5-days climatological seasonal cycle averaged over an extended Indian domain $\left(65^{\circ}-100^{\circ} \mathrm{E} /\right.$ $5^{\circ}-30^{\circ} \mathrm{N}$, see inset map for box limits). (d) Same as (c), for the land area of the box only.

Figure 10. (a) JJAS mean climatological differences of surface temperature $\left({ }^{\circ} \mathrm{C}\right.$, shaded) and SLP (hPa, contours) between ALB1 and ALB1HR experiments. (b) JJAS mean climatological differences of precipitation ( $\mathrm{mm} /$ day, shaded) and $850 \mathrm{hPa}$ wind (m/s, vectors) differences between ALB1 and ALB1HR. (c) Same as (a), but between ALB2HR and ALB1HR. (d) Same as (b), but between ALB2HR and ALB1HR. (e) Same as (a), but between ALB2HR and ALB1. (f) Same as (b), but between ALB2HR and ALB1. (g) JJAS mean climatological biases of surface temperature $\left({ }^{\circ} \mathrm{C}\right.$, shaded) and SLP (hPa, contours) of ALB2HR compared to ERA-Interim. (h) JJAS mean climatological biases of precipitation ( $\mathrm{mm} /$ day, shaded) and $850 \mathrm{hPa}$ wind $(\mathrm{m} / \mathrm{s}$, vectors) ALB2HR biases compared to TRMM and ERA-Interim, respectively. 


\begin{tabular}{|c|l|}
\hline Processes & \\
\hline ISM & Indian Summer Monsoon \\
\hline ITCZ & Inter-Tropical Convergence Zone \\
\hline LPS & Low-Pressure System \\
\hline Variables & \\
\hline TT & Tropospheric Temperature \\
\hline SST & Sea Surface Temperature \\
\hline LST & Land Surface Temperature \\
\hline SW & Short-Wave \\
\hline SLP & Sea-Level Pressure \\
\hline Regions & \\
\hline ME & Middle-East \\
\hline IO & Indian Ocean \\
\hline BoB & Bay of Bengal \\
\hline AS & Arabian Sea \\
\hline Models & \\
\hline CGCM & Coupled Global/General Climate Model \\
\hline RCM & Regional Climate Model \\
\hline GCM & General Circulation Model \\
\hline CTCM & Coupled Tropical Channel Model \\
\hline NOW & NEMO-OASIS-WRF \\
\hline RRTM & Rapid Radiative Transfer Model \\
\hline BMJ & Betts-Miller-Janjic \\
\hline YSU & Yonsei University \\
\hline LSM & Land Surface Model \\
\hline Observations & \\
\hline MODIS & MODerate resolution Imaging Spectroradiometer \\
\hline IGBP & International Geosphere-Biosphere Program \\
\hline AVHRR & Advanced Very High-Resolution Radiometer \\
\hline TRMM & Tropical Rainfall Measuring Mission \\
\hline GPCC & Global Precipitation Climatology Centre \\
\hline & \\
\hline
\end{tabular}

Table 1: List of the acronyms used. 


\begin{tabular}{|c|c|l|c|c|c|}
\hline & Name & Model & $\begin{array}{c}\text { Duration } \\
\text { (years })\end{array}$ & Resolution & Setup \\
\hline $\begin{array}{c}\text { Reference } \\
\text { simulation }\end{array}$ & ALB1 & NOW & 20 & $0.75^{\circ}$ & $\begin{array}{c}\text { Reference } \\
\text { (described in 2a) }\end{array}$ \\
\hline \multirow{2}{*}{$\begin{array}{c}\text { Sensitivity } \\
\text { Set }\end{array}$} & FORC & WRF & 10 & $0.75^{\circ}$ & $\begin{array}{c}\text { REF }+ \\
\text { Reynolds SST }\end{array}$ \\
\cline { 2 - 6 } & HIRES & WRF & 10 & $0.25^{\circ}$ & $\begin{array}{c}\text { FORC }+ \\
0.25^{\circ} \text {-resolution }\end{array}$ \\
\cline { 2 - 6 } & RAD & WRF & 10 & $0.75^{\circ}$ & $\begin{array}{c}\text { FORC }+ \\
\text { Kain-Fritsh CU }\end{array}$ \\
\hline \multirow{2}{*}{\begin{tabular}{c} 
Albedo Set \\
\cline { 2 - 6 }
\end{tabular}} & ALB2 & NOW & 20 & $0.75^{\circ}$ & $\begin{array}{c}\text { FORC }+ \\
\text { Dudhia SW }\end{array}$ \\
\cline { 2 - 6 } & ALB 3 & NOW & 20 & $0.75^{\circ}$ & $\begin{array}{c}\text { REF }+ \\
\text { RODIS }+ \\
\text { MODIS albedo }\end{array}$ \\
\hline \multirow{2}{*}{$\begin{array}{c}\text { High-Resolution } \\
\text { Set }\end{array}$} & ALB1HR & NOW & 20 & $0.25^{\circ}$ & $\begin{array}{c}\text { ALB1 }+ \\
0.25^{\circ} \text {-resolution }\end{array}$ \\
\cline { 2 - 6 } & ALB2HR & NOW & 20 & $0.25^{\circ}$ & $\begin{array}{c}\text { ALB2 }+ \\
0.25^{\circ} \text {-resolution }\end{array}$ \\
\hline
\end{tabular}

Table 2: Summary of tropical-channel simulations.

Differences between the simulations configurations are given in the "Setup" column. 

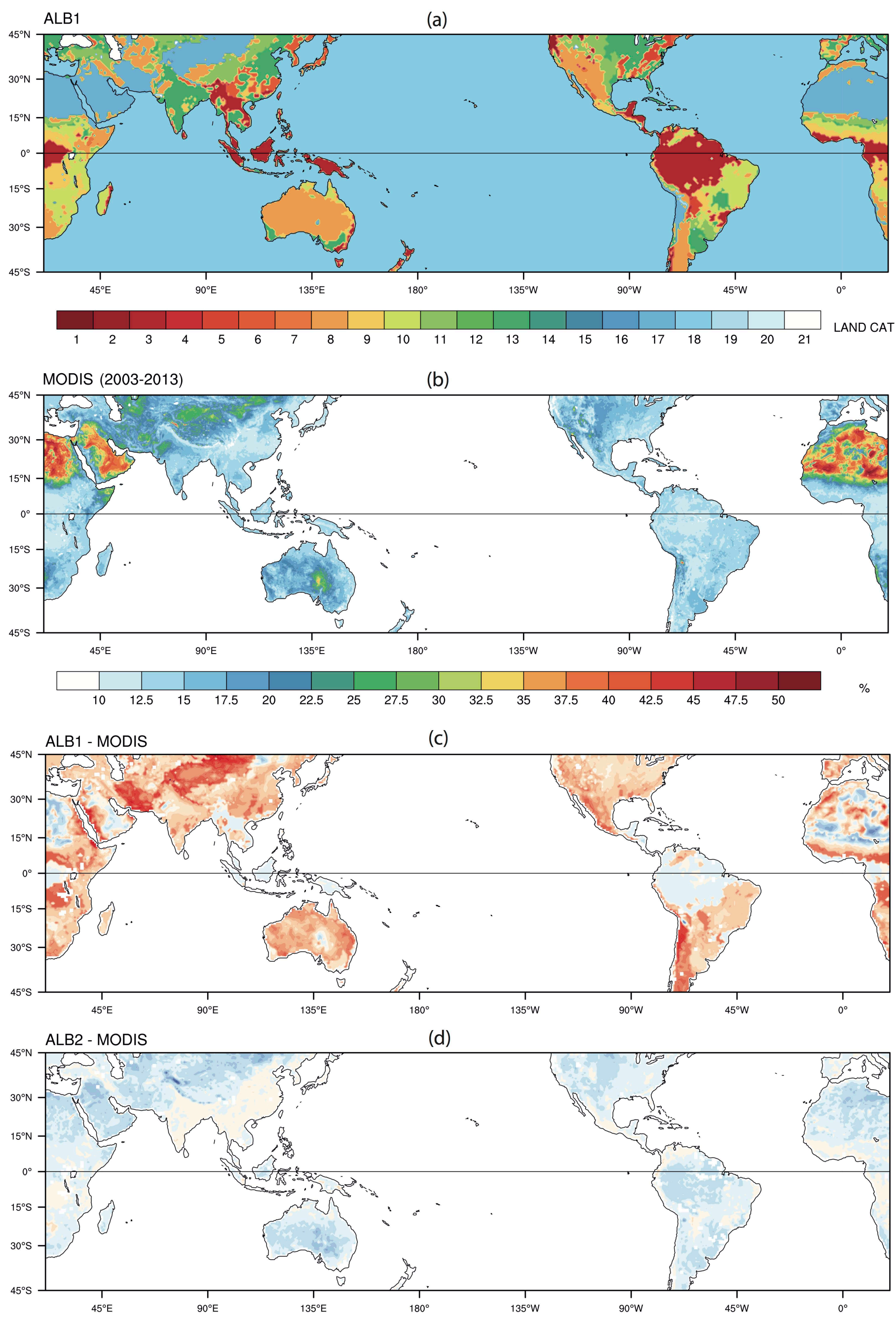

\begin{tabular}{|l|l|l|l|l|l|l|l|l|l|l|l|l|l|l|l|l|l|l|l|l|l|}
\hline & & & & & & & & & & & & & & & & & & & & & \\
\hline
\end{tabular}

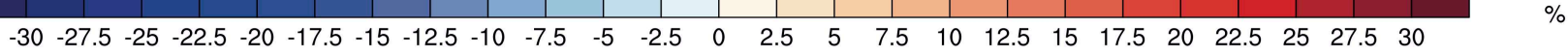

Figure 1. (a) MODIS-IGBP dominant land-use categories. (b) Annual snow-free black-sky broadband SW land albedo from MODIS product (\%). Note that in all figures, ocean albedo is not displayed for clarity. (c) Time-average difference between ALB1 albedo and MODIS snow-free product (\%). (d) Same as (c) for ALB2 (\%). 
Surface temperature and sea-level pressure

(a)
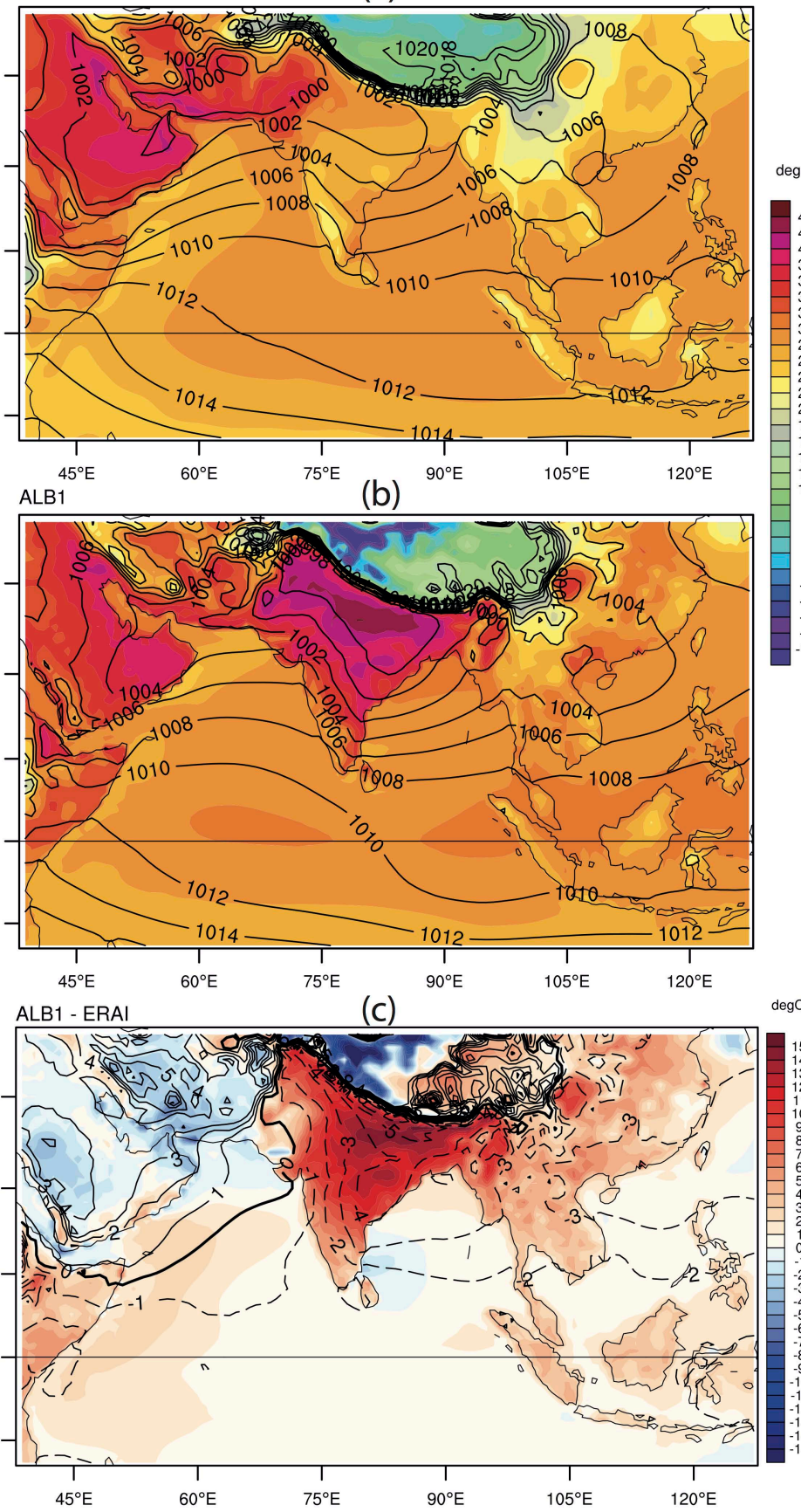

Precipitation and $850 \mathrm{hPa}$ wind

(d)

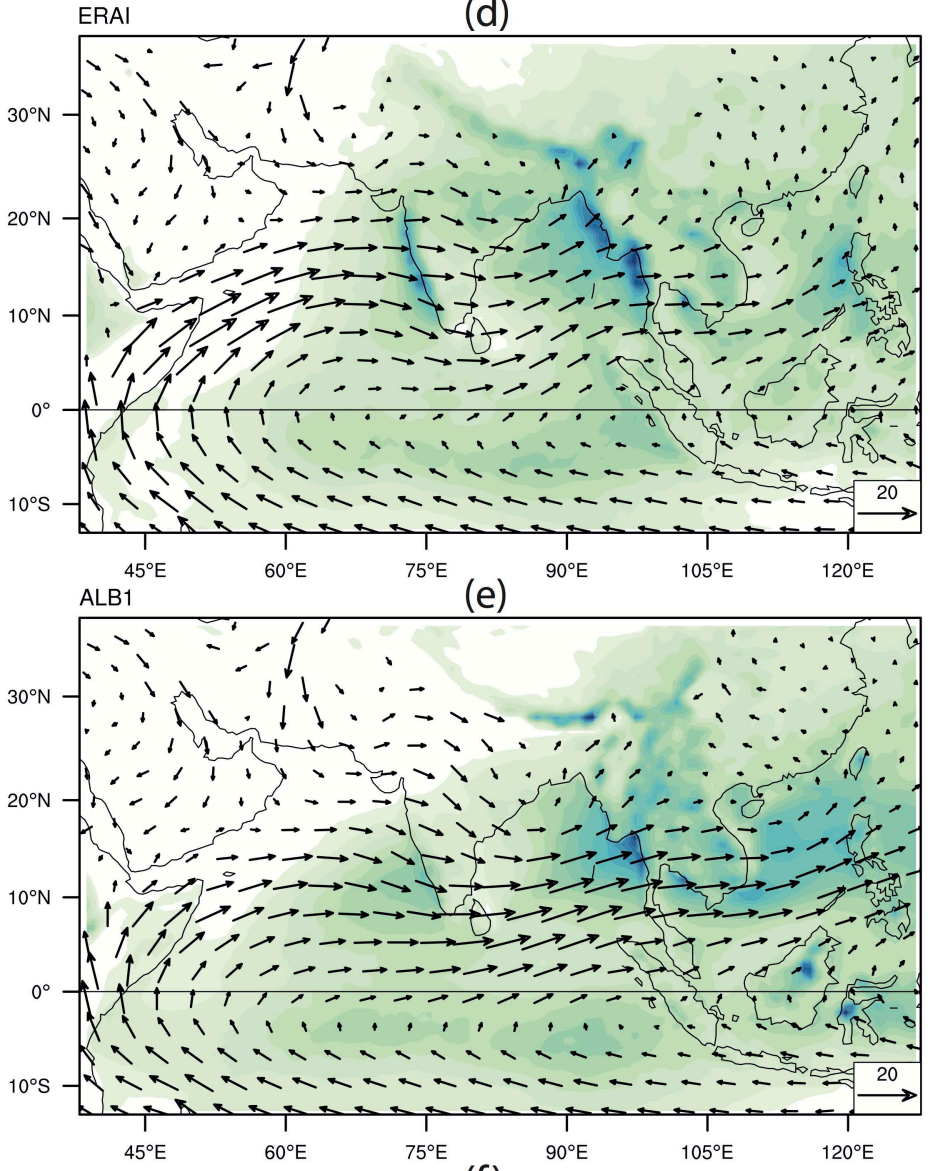

ALB1 - ERAI

(f)

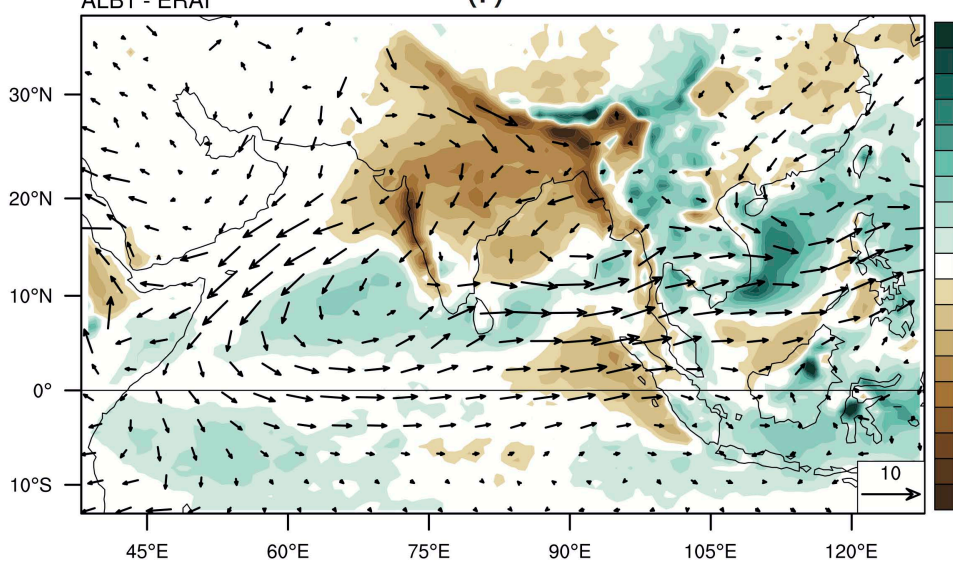

Figure 2. (a) Summer monsoon (JJAS) mean climatological ERA-Interim surface temperature $\left({ }^{\circ} \mathrm{C}\right.$, shaded) and SLP $(\mathrm{hPa}$, contours; contours greater than $1020 \mathrm{hPa}$ are not drawn for clarity). (b) Same as (a) for ALB1. (c) ALB1 surface temperature $\left({ }^{\circ} \mathrm{C}\right.$, shaded) and SLP (hPa, contours) biases compared to ERA-Interim (contours bias greater than $\pm 8 \mathrm{hPa}$ are not drawn for clarity). (d) TRMM precipitation (mm/day, shaded) and ERA-Interim $850 \mathrm{hPa}$ wind (m/s, vectors). (e) Same as (d) for ALB1. (f) Biases of ALB1 precipitation and wind computed as the difference between (b) and (a). 


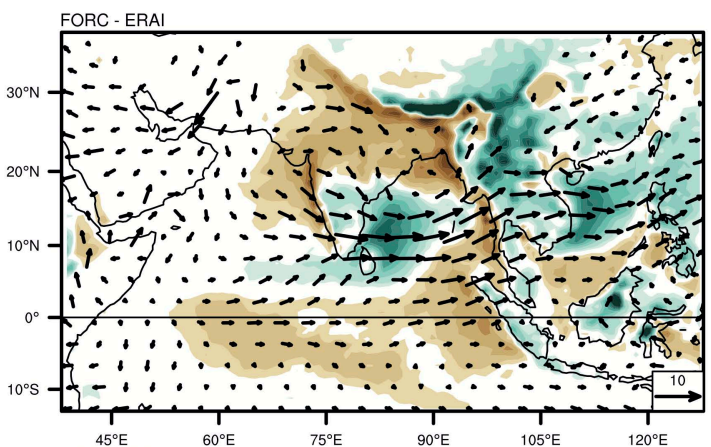

(a)
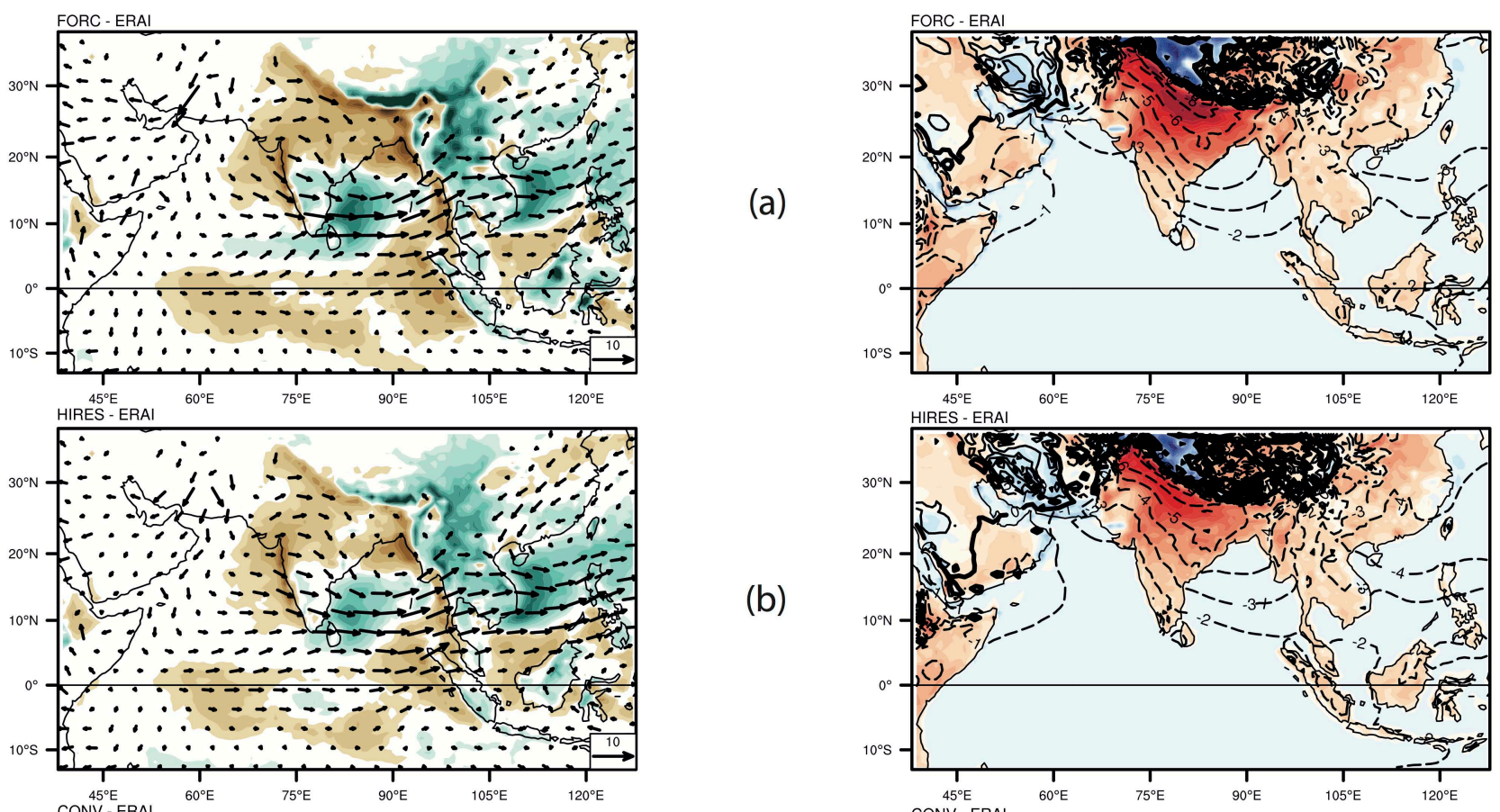

(b)

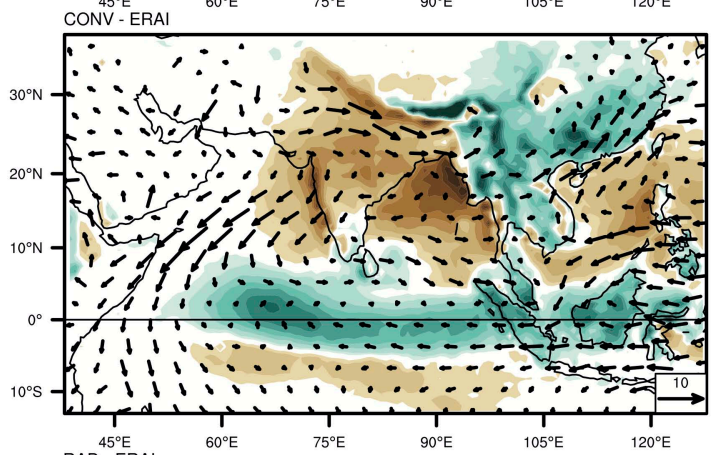

(c)

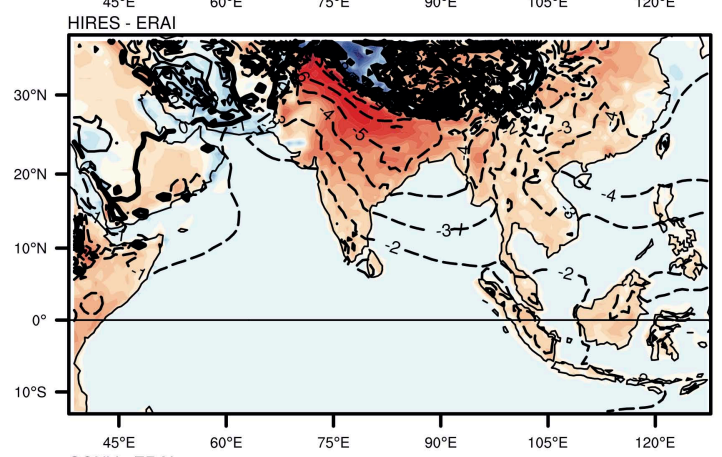

RAD - ERA

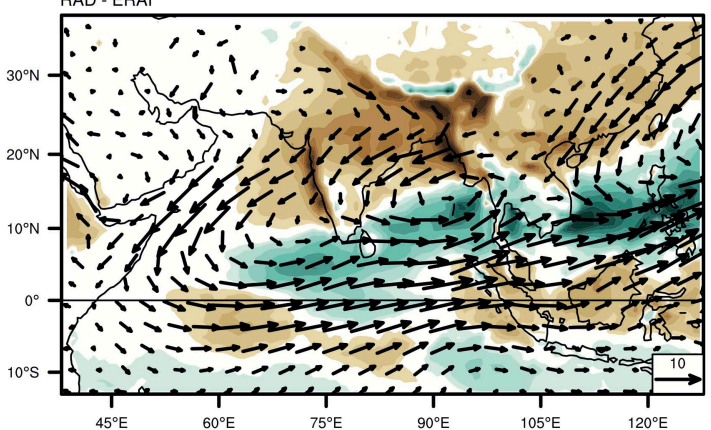

(d)
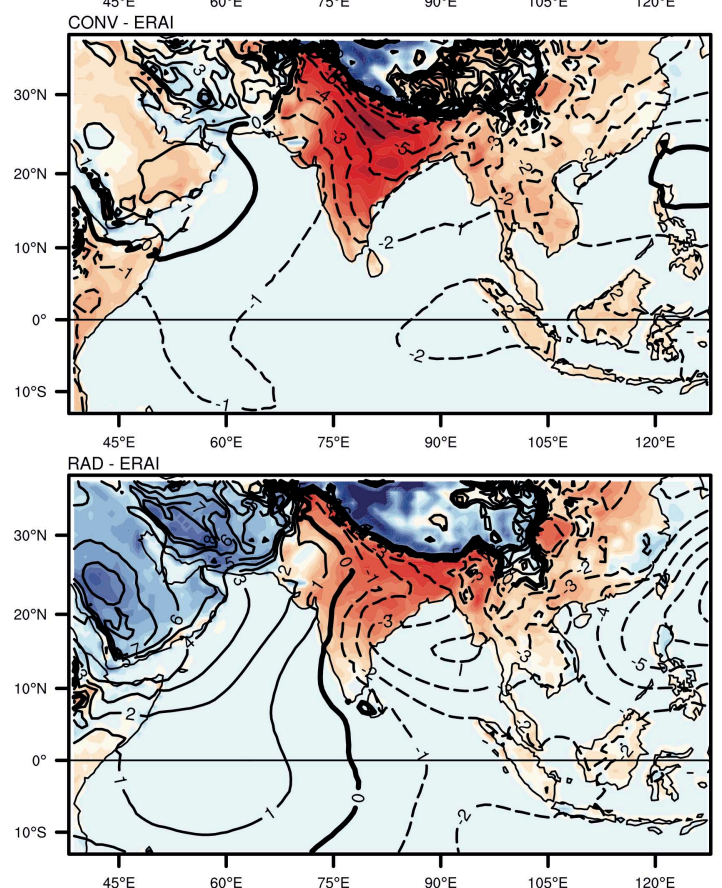

Figure 4. (left column) JJAS rainfall $(\mathrm{mm} / \mathrm{d}$, shaded) and $850 \mathrm{hPa}$ wind $(\mathrm{m} / \mathrm{s}$, vectors) biases of the various sensitivity experiments, compared to TRMM and ERA-Interim datasets, respectively: (a) FRC, (b) HIRES, (c) CONV and (d) RAD; see Table 2 for the description of these experiments. (right column) JJAS surface temperature $\left({ }^{\circ} \mathrm{C}\right.$, shaded) and SLP ( $\mathrm{hPa}$, contours) biases compared to ERAInterim dataset :(a) FRC, (b) HIRES, (c) CONV and (d) RAD. 

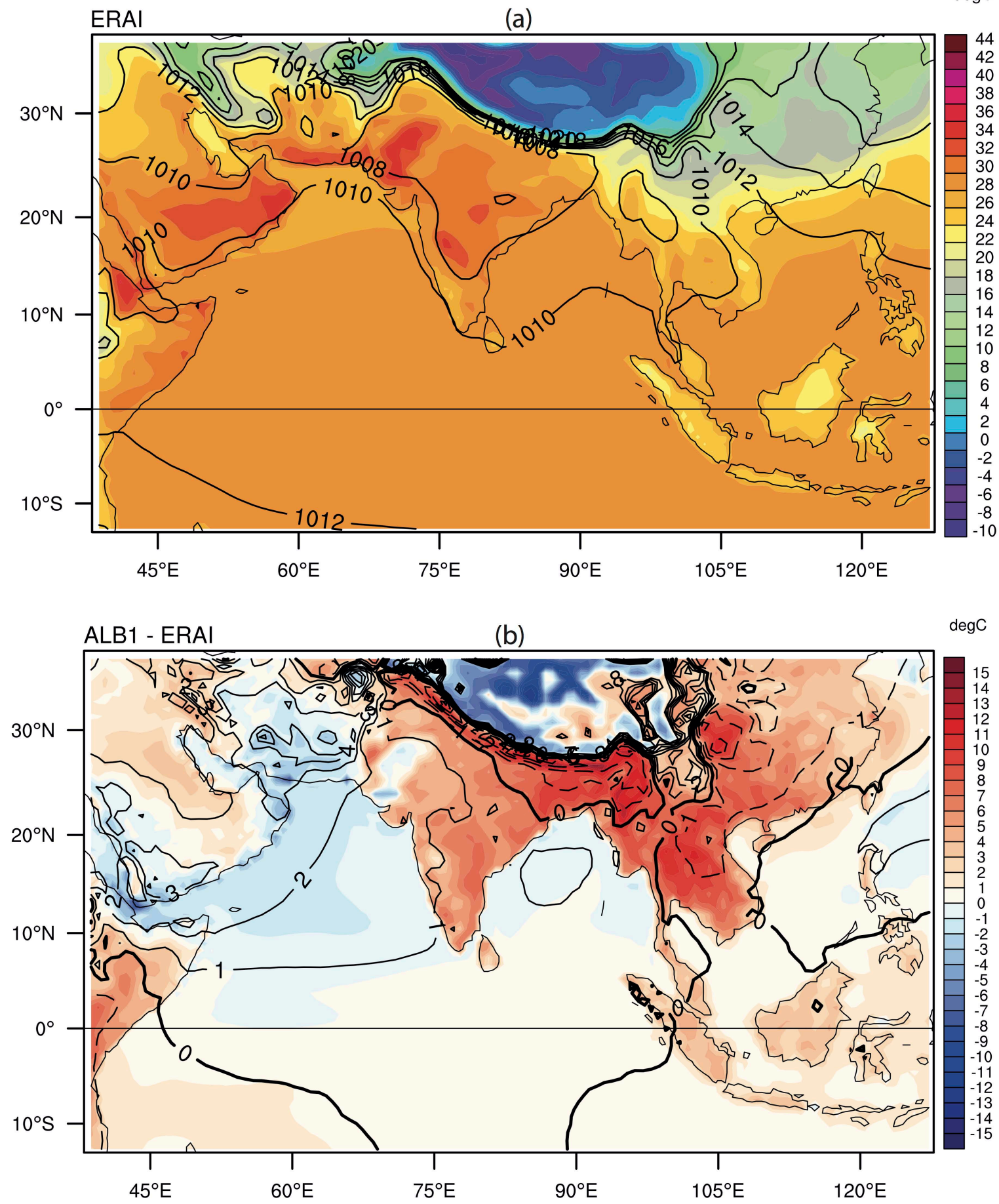

Figure 5. (a) Pre-monsoon (MAM) mean climatological ERA-Interim surface temperature $\left({ }^{\circ} \mathrm{C}\right.$, shaded) and SLP (hPa, contours). (b) Biases of ALB1 surface temperature and SLP (computed as the difference between (b) and (a)). 

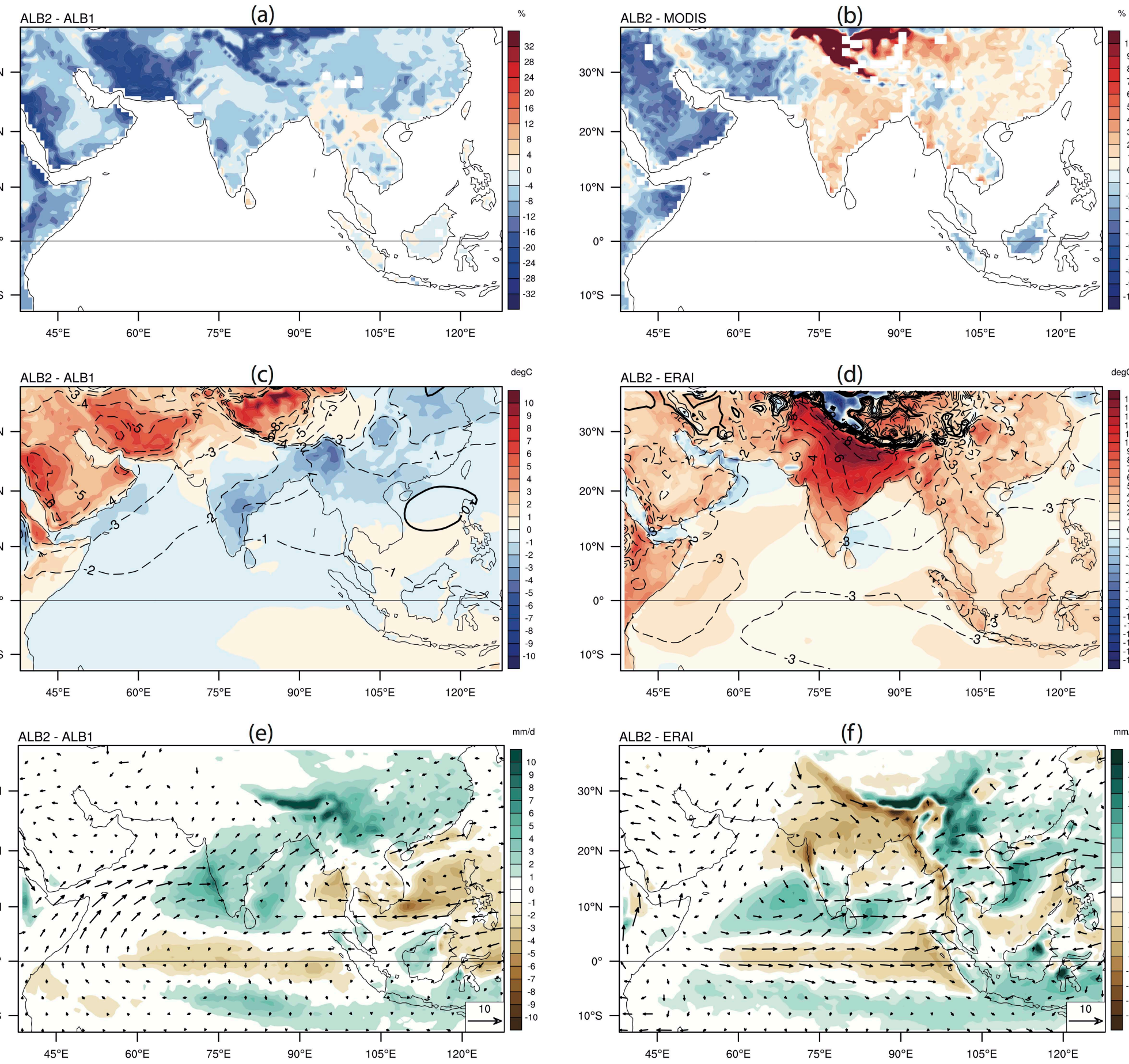

Figure 6. (a) JJAS mean climatological albedo difference between ALB2 and ALB1 (unit \%). (b) ALB2 albedo bias compared to MODIS (unit \%). (c) Surface temperature $\left({ }^{\circ} \mathrm{C}\right.$, shaded) and SLP (hPa, contours) differences between ALB2 and ALB1. (d) ALB2 surface temperature $\left({ }^{\circ} \mathrm{C}\right.$, shaded) and SLP (hPa, contours) biases compared to ERA-Interim. (e) Precipitation (mm/day, shaded) and 850hPa wind (m/s, vectors) differences between ALB2 and ALB1. (f) ALB2 precipitation (mm/day, shaded) and $850 \mathrm{hPa}$ wind (m/s, vectors) biases compared to ERAInterim. 
(a)

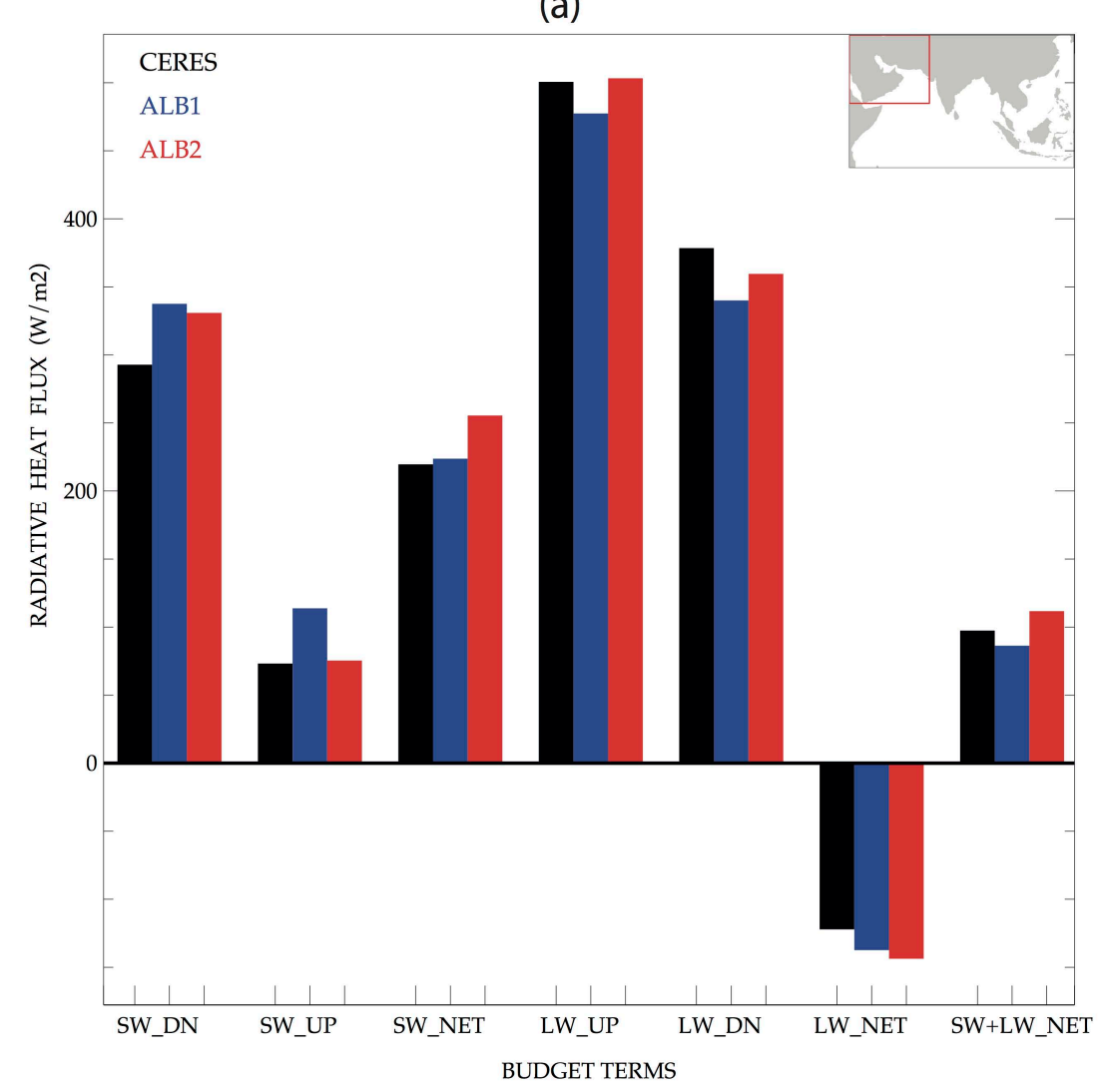

(b)

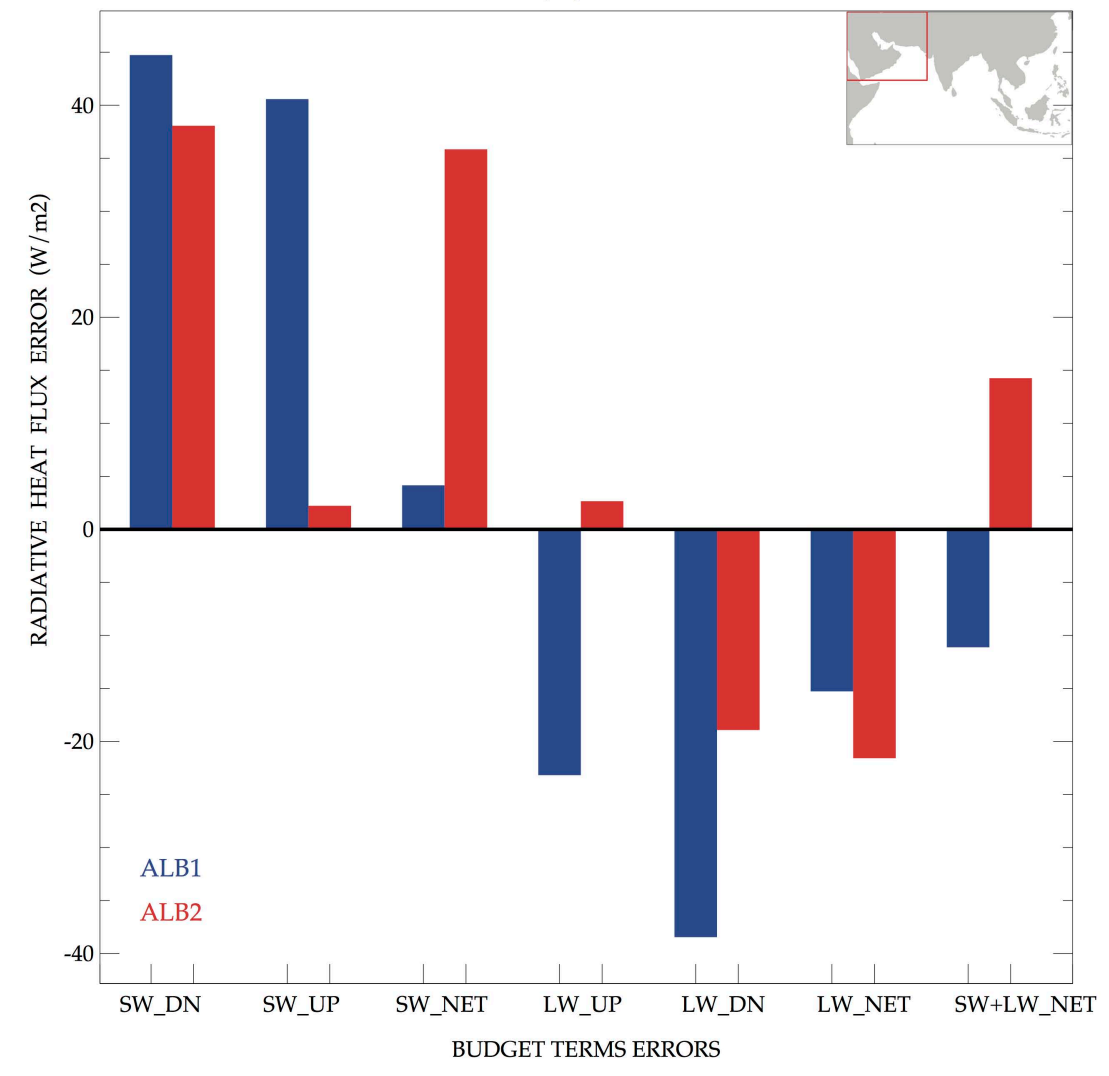

Figure 7. (a) JJAS mean climatological surface radiative heat fluxes averaged over the "Middle East" region (see inset map for box limits, only the land points in the box are considered). Black, blue and red bars show CERES-EBAF, ALB1 and ALB2 estimates, respectively. The bars from left to right are for downward shortwave (SW_DN), upward shortwave (SW_UP), net shortwave (SW_NET), upward longwave (LW_UP), downward longwave (LW_DN), net longwave (LW_NET) and total radiative heat fluxes (SW+LW_NET) at land surface (in $\mathrm{W} / \mathrm{m}^{2}$ ). (b) same as (a), for ALB1 and ALB2 errors compared to CERES-EBAF dataset. 


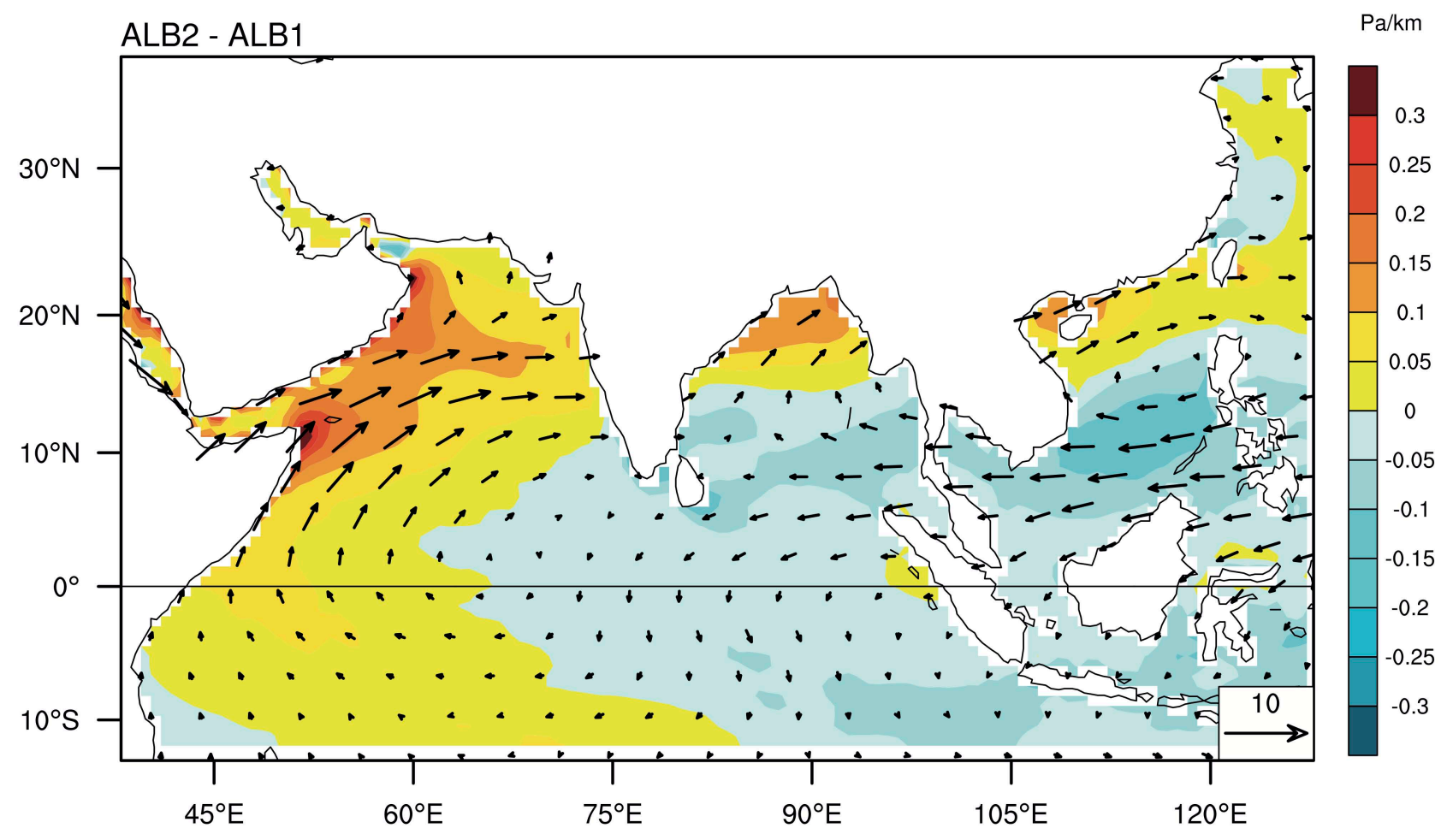

Figure 8. JJAS mean climatological differences of SLP gradient $(\mathrm{Pa} / \mathrm{km}$, shaded) and $850 \mathrm{hPa}$ wind (m/s, vectors) differences between ALB2 and ALB1 experiments. Land surfaces are masked for clarity. 

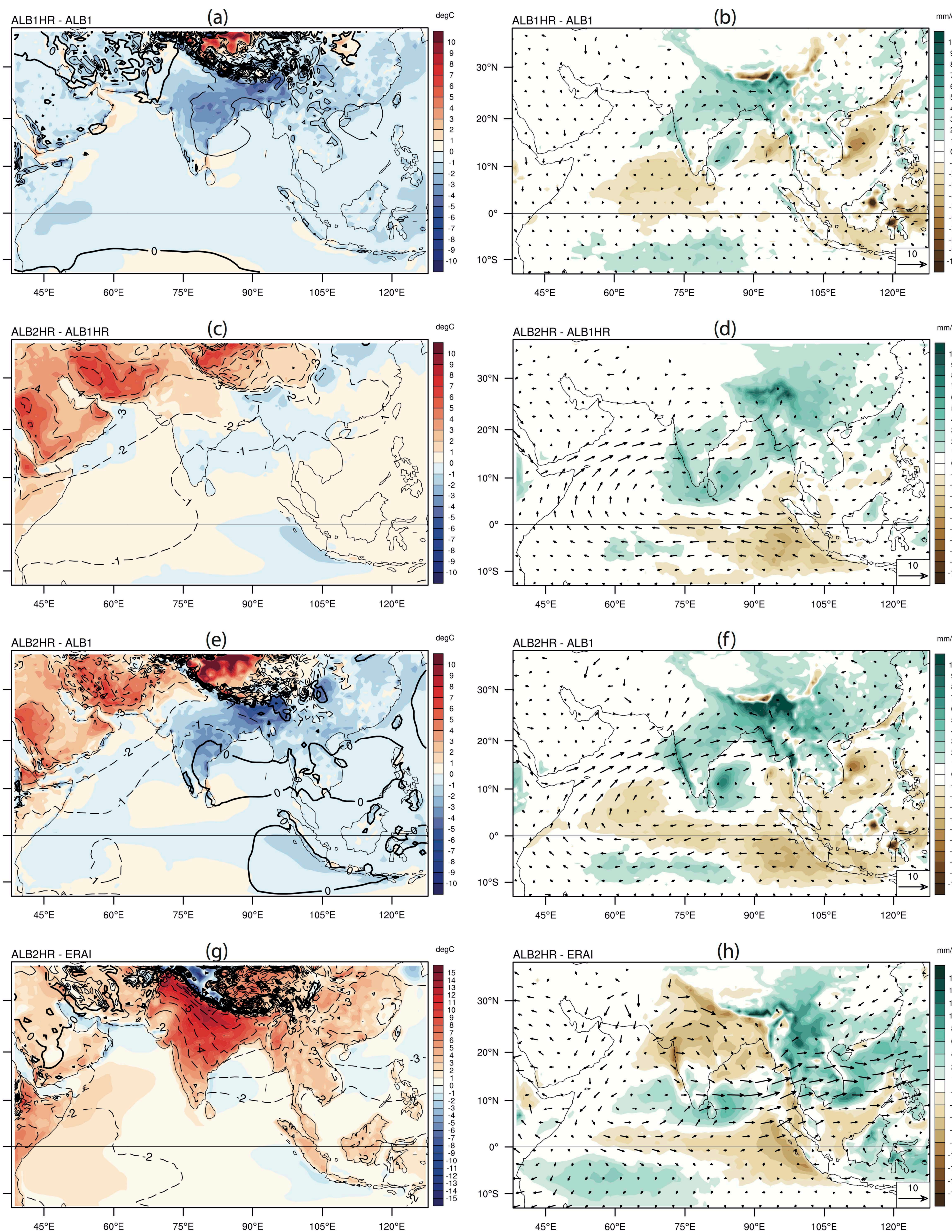

Figure 10. (a) JJAS mean climatological differences of surface temperature $\left({ }^{\circ} \mathrm{C}\right.$, shaded) and SLP (hPa, contours) between ALB1 and ALB1HR experiments. (b) JJAS mean climatological differences of precipitation $(\mathrm{mm} /$ day, shaded) and 850hPa wind (m/s, vectors) differences between ALB1 and ALB1HR. (c) Same as (a), but between ALB2HR and ALB1HR. (d) Same as (b), but between ALB2HR and ALB1HR. (e) Same as (a), but between ALB2HR and ALB1. (f) Same as (b), but between ALB2HR and ALB1. (g) JJAS mean climatological biases of surface temperature $\left({ }^{\circ} \mathrm{C}\right.$, shaded) and SLP ( $\mathrm{hPa}$, contours) of ALB2HR compared to ERAInterim. (h) JJAS mean climatological biases of precipitation (mm/day, shaded) and $850 \mathrm{hPa}$ wind (m/s, vectors) ALB2HR biases compared to TRMM and ERAInterim, respectively. 